\title{
SOCS1-targeted therapy ameliorates renal and vascular oxidative stress in diabetes via STAT1 and PI3K inhibition
}

\author{
Laura Lopez-Sanz $z^{1,2,3} \cdot$ Susana Bernal ${ }^{1,2,3} \cdot$ Carlota Recio $^{1,2,3} \cdot$ Iolanda Lazaro $^{1,2} \cdot$ Ainhoa Oguiza $^{1,2,3} \cdot$ Ana Melgar $^{1,2}$. \\ Luna Jimenez-Castilla ${ }^{1,2} \cdot$ Jesus Egido ${ }^{2,3} \cdot$ Carmen Gomez-Guerrero ${ }^{1,2,3}$
}

Received: 28 July 2017 / Revised: 30 January 2018 / Accepted: 31 January 2018 / Published online: 14 March 2018

(c) United States \& Canadian Academy of Pathology 2018

\begin{abstract}
Oxidative stress resulting from excessive production of reactive oxygen species (ROS) or impaired antioxidant defenses is closely related to the development of diabetic vascular complications, including nephropathy and atherosclerosis. Chronic activation of Janus kinase/Signal transducer and activator of transcription (JAK/STAT) signaling pathway contributes to diabetic complications by inducing expression of genes involved in cell proliferation, fibrosis, inflammation, and oxidative stress. Suppressors of cytokine signaling (SOCS) family of endogenous JAK/STAT regulators is an attractive target for therapeutic intervention. We investigated the beneficial effect of two different SOCS1-targeted therapies (adenovirusmediated gene transfer and kinase-inhibitory region peptidomimetic) to combat oxidative stress injury in an experimental diabetes model of concomitant renal and macrovascular disease (streptozotocin-induced diabetic apolipoprotein E-deficient mouse). Diabetes resulted in progressive alteration of redox balance in mice, as demonstrated by increased ROS levels and decreased antioxidant activity, which ultimately led to renal dysfunction and vascular injury. The molecular and pathological alterations in early diabetes were partially reversed by preventive intervention with SOCS1-targeted therapies. Importantly, SOCS1 peptidomimetic provided reno- and atheroprotection in diabetic mice even in a setting of established disease. Compared with untreated controls, kidney and aorta from SOCS1-treated mice exhibited significantly lower levels of superoxide anion, DNA oxidation marker and NADPH oxidase (Nox) subunits, along with higher expression of antioxidant enzymes. These trends correlated with a reduction in parameters of renal damage (albuminuria, creatinine and tubular injury), atherosclerosis (lesion size) and inflammation (leukocytes and chemokines). Mechanistic studies in renal, vascular and phagocytic cells exposed to cytokines and high-glucose showed that SOCS1 blocked ROS generation by inhibiting both Nox complex assembly and Nox subunit expression, an effect mediated by inactivation of JAK2, STAT1, and PI3K signaling pathways. This study provides evidence for SOCS1-targeted therapies, especially SOCS1 peptidomimetic, as an alternative antioxidant strategy to limit the progression of diabetic micro- and macrovascular complications.
\end{abstract}

\section{Introduction}

These authors contributed equally: Susana Bernal, Carlota Recio

Carmen Gomez-Guerrero

cgomez@fjd.es

c.gomez@uam.es

1 Renal and Vascular Inflammation Group, Fundacion Jimenez Diaz University Hospital-Health Research Institute (FIIS-FJD), Autonoma University of Madrid (UAM), Madrid, Spain

2 Division of Nephrology and Hypertension, Fundacion Jimenez Diaz University Hospital-Health Research Institute (FIIS-FJD), Autonoma University of Madrid (UAM), Madrid, Spain

3 Spanish Biomedical Research Centre in Diabetes and Associated Metabolic Disorders (CIBERDEM), Madrid, Spain
Diabetes-related vascular complications, including atherosclerosis and kidney disease, are the major causes of morbidity and mortality among diabetic patients [1]. Accelerated atherosclerosis in large arteries increases the risk of cardiovascular disease in diabetic patients, while diabetic nephropathy largely contributing to end-stage renal disease is also an important risk factor for macrovascular complications [2]. Besides the interactions between metabolic, hemodynamic, genetic, and environmental factors, increased inflammation and oxidative stress are considered critically important to the progression of atheroma plaques and kidney injury in type 1 and type 2 diabetes [3]. In fact, chronic hyperglycemia in combination with growth factors, 
hormones and cytokines act on cells to impair redox balance due to either increased generation of reactive oxygen species (ROS) or insufficient antioxidant defense systems, thus resulting in oxidative damage of biological macromolecules (lipids, proteins, and DNA) and tissue injury [4-6].

Potential sources of ROS include mitochondrial respiratory chain, xanthine oxidase, several hemoproteins, uncoupled NO synthase, and NADPH oxidase (Nox). Nox is a multi-subunit enzyme that catalyzes generation of $\mathrm{O}_{2} \bullet^{-}$ by reduction of $\mathrm{O}_{2}$ using either NADPH or NADH as a substrate $[4,6]$. Collectively known as the Nox family, seven isoforms are expressed in mammals: Nox1, Nox2 (formerly known as gp91 $1^{\text {phox }}$ ), Nox3, Nox4, Nox5, and Dual oxidase proteins (Duox1 and Duox2). Other components of the enzyme complex, including the transmembrane protein $\mathrm{p} 22^{\text {phox }}$, and the regulatory subunits $\mathrm{p} 40^{\text {phox }}$, $\mathrm{p} 47^{\text {phox }}, \mathrm{p} 67^{\text {phox }}$, Nox organizer protein 1 (NoxO1), Nox activator protein 1 (NoxA1), small GTPase Rac, and polymerase $\delta$-interacting protein 2 (Poldip2), are also characterized [7-9]. Nox1, Nox2, and Nox4 subunits are predominantly expressed in the vasculature and kidney, while other homologs have not been found or are expressed at very low levels $[6,8]$. In phagocytes, Nox 2 catalytic activity is initiated by translocation to the membrane of cytosolic subunits $\mathrm{p} 47^{\text {phox }}$ and $\mathrm{p} 67^{\text {phox }}$. In vascular and renal cells, Nox 1 and Nox 2 are similarly regulated by the $447^{\text {phox }}$ and $67^{\text {phox }}$ homologs NoxO1 and NoxA1, while Nox4 activity predominantly requires Poldip $2[6,9,10]$. In the setting of diabetes, previous studies in animal models identified a major pathological role for Nox1-derived ROS in diabetes-accelerated atherosclerosis [6, 11], whereas Nox 4 and Nox 1 are the main isoforms involved in kidney disease in type 1 and type 2 diabetes [12-15].

Multiple ways are involved in assembly, activation, and expression of Nox complex, including the phosphorylation of cytosolic regulatory subunits (e.g. by protein kinase C, phosphatidylinositol 3-kinase (PI3K), mitogen-activated protein kinases, and Janus tyrosine kinase (JAK)) and the transcriptional regulation of Nox subunits (e.g. by nuclear factor- $\mathrm{\kappa B}$, activator protein-1, and signal transducers and activators of transcription (STAT)) [7, 8]. Conversely, excess amounts of Nox-derived ROS have been demonstrated to directly or indirectly modulate activation of kinases and transcription factors in various cell types following the exposure to diabetic conditions, which eventually cause inflammation, proliferation, fibrosis, endothelial dysfunction, and aberrant angiogenesis [4, 16].

The JAK/STAT pathway is an essential intracellular mechanism activated by cytokines and diabetic factors that regulates cell activation, proliferation, recruitment, migration, and differentiation [17]. JAK/STAT members are composed of four kinases (JAK1-3 and TYK2) and seven transcription factors (STAT1-4, 5A, 5B, and 6), which are controlled in a classical negative-feedback loop by the suppressors of cytokine signaling (SOCS) family (SOCS1-7 and CIS) $[18,19]$. Dysregulated JAK/STAT/SOCS pathway contributes to the pathogenesis of cancer, autoimmune and inflammatory disorders including diabetes, and has been claimed as a novel molecular target for anti-inflammatory therapy in chronic diseases [19-21].

Current treatment of diabetes based on the integrated control of glycemia, blood pressure, and lipids is insufficient to prevent the progression of chronic complications in a significant proportion of patients [22], and hence new strategies are needed to retard cardiovascular disease or renal function decline. Because the relationship between oxidative stress and JAK2/STAT1 pathway is a common mechanism of diabetic tissue damage [20,21], this study aimed to establish the role of SOCS1, one of the most relevant SOCS family members, on redox regulation during development of diabetic complications. Previous animal studies from our group demonstrated that therapeutic targeting of SOCS family prevents tissue injury in both nondiabetic [23-25] and diabetic conditions [26-28]. Therefore, this work investigates the antioxidant effects of two different SOCS1-based strategies (adenovirus-mediated gene transfer and peptidomimetic of the kinase-inhibitory region) in the setting of diabetic micro- and macrovascular complications. We therefore analyzed the ability of SOCS1 to blunt diabetes-induced oxidative stress in vivo using a model of combined hyperglycemia and hyperlipidemia (streptozotocin (STZ)-induced diabetic apolipoprotein E (apoE)-deficient mice) characterized by accelerated renal and vascular injury with similarities to human diabetic nephropathy and atherosclerosis [29], and also in vitro in cultured cells under inflammatory/hyperglycemic conditions.

\section{Material and methods}

\section{Diabetes mouse models and treatments}

Animal studies conform to the Directive 2010/63/EU of the European Parliament and were approved by the Institutional Animal Care and Use Committee (FIIS-Fundacion Jimenez Diaz) and Comunidad de Madrid (Ref. PROEX 116/16).

\section{Study I: Early intervention model}

ApoE-deficient mice (8-week-old males; Jackson Laboratory, Bar Harbor, ME) were rendered diabetic by two intraperitoneal injections of STZ $(125 \mathrm{mg} / \mathrm{kg} /$ day in citrate buffer $\mathrm{pH}$ 4.5; Sigma-Aldrich, St. Louis, MO) on consecutive days, resulting in a model of insulin deficiency [26-28]. Animals were maintained on standard diet without 
water restriction and were monitored every $2-3$ days for body weight and non-fasting blood glucose. Severely hyperglycemic mice (glucose $>29 \mathrm{mmol} / \mathrm{L}$ ) received insulin (1-1.5 IU) to maintain blood glucose levels within a more tolerable range. Mice with overt diabetes (glucose $>19.4$ $\mathrm{mmol} / \mathrm{L}$ ) were randomized to receive: (i) a single intravenous injection of recombinant adenovirus encoding mouse SOCS1 (Ad-S1 group, $1 \times 10^{12}$ viral particles $/ \mathrm{kg} ; n=8$ ), empty vector (Ad-null group, $1 \times 10^{12}$ viral particles $/ \mathrm{kg} ; n=$ 8) or saline (Control group; $n=6$ ); (ii) multiple intraperitoneal injections of peptidomimetic of SOCS1-kinaseinhibitory region (miS1 group, $3 \mathrm{mg} / \mathrm{kg} / \mathrm{day} ; n=6$ ) or vehicle ( $0.1 \%$ DMSO; Veh group, $n=6)$ every second day. All diabetic groups and age-matched non-diabetic mice $(n$ $=6$ ) were analyzed after 6 weeks of intervention. Cloning and production of SOCS1-encoding adenovirus, synthesis of SOCS1 peptidomimetic and their biodistribution in mouse tissues including kidney and aorta were previously described [24, 26, 27].

\section{Study II: Late intervention model}

Diabetes was induced in 22-week-old apoE-deficient mice (same protocol as described for study I). After 2 weeks of STZ injection, overtly diabetic mice were randomized to receive SOCS1 peptidomimetic (miS1 group, $3 \mathrm{mg} / \mathrm{kg} /$ day; $n=10$ ), mutant inactive peptide (Mut group, $3 \mathrm{mg} / \mathrm{kg} / \mathrm{day}$; $n=7)$ or vehicle $(0.1 \%$ DMSO; Veh group, $n=10)$ via intraperitoneal every second day for 10 weeks.

\section{Sample preparation and histology}

At the study endpoint, 16-h-fasted mice were anesthetized (100 mg/kg ketamine and $15 \mathrm{mg} / \mathrm{kg}$ xylazine), saline-perfused, and killed. Blood and urine samples were collected for measurements of oxidative DNA damage marker (8hydroxy-2'-deoxyguanosine, 8-OHdG; ELISA StressMarq Biosciences Inc. Victoria, Canada), total antioxidant capacity (OxiSelect TAC colorimetric assay; Cell Biolabs Inc., San Diego CA), urine albumin/creatinine ratio (UACR) and serum creatinine (ELISA Abcam, Cambridge, UK). Mouse peritoneal macrophages were collected by peritoneal lavage as described previously [24] and processed for RNA isolation. Dissected kidneys were snap-frozen for RNA isolation or formalin-fixed, paraffin-embedded and sectioned for histological analysis. The aortic root embedded in OCT medium (Sakura Finetek, Flemingweg, The Netherlands) was sectioned into $8 \mu \mathrm{m}$ slices for histological analysis; the thoracoabdominal aorta was processed for RNA isolation.

Kidney sections were stained with Masson's trichrome for quantitative assessment of extracellular matrix deposition within glomeruli and tubulointerstitium. Aortic sections were stained with Oil-red-O/hematoxylin and Masson's trichrome for quantification of the atherosclerotic lesion areas. Intracellular superoxide anion $\left(\mathrm{O}_{2} \bullet^{-}\right)$in renal and aortic sections was visualized using the oxidation-sensitive fluorescent probe dihydroethidium (DHE; $2 \mu \mathrm{mol} / \mathrm{L}$; Life Technologies, Carlsbad, CA) followed by 4',6-diamidino-2phenylindole (DAPI) nuclear counterstain [30]. As negative control, adjacent sections were pretreated with cellpermeable polyethylene glycol-superoxide dismutase (PEG-SOD; $500 \mathrm{U} / \mathrm{mL}$ ) to determine the specificity of the fluorescence signal. Immunodetection of total macrophages (Moma-2; Serotec, Oxford, UK), 8-OHdG (Abcam), Nox1, and Nox4 (Santa Cruz Biotechnology, Santa Cruz, CA) was assessed by indirect immunoperoxidase. Positive staining was quantified using Image Pro-Plus software (Media Cybernetics, Bethesda, MD) and expressed as percentage of total area and number of positive cells (per glomerular cross-section or per $\mathrm{mm}^{2}$ ).

\section{Cell cultures}

Primary vascular smooth muscle cells (VSMC) were isolated from mouse thoracic aorta by enzymatic digestion with collagenase type II and maintained in Dulbecco's modified Eagle medium (DMEM) containing 10\% fetal bovine serum (FBS), $100 \mathrm{U} / \mathrm{mL}$ penicillin, $100 \mu \mathrm{g} / \mathrm{mL}$ streptomycin, and $2 \mathrm{mmol} / \mathrm{L}$ glutamine (Life Technologies, Rockville, MD) [23, 27]. VSMC were characterized by phase-contrast microscopy and immunostaining (positive for $\alpha$-actin and negative for factor VIII) and used between the second and seventh passage. SV-40 immortalized murine kidney proximal tubular epithelial (MCT) cells (originally provided by Dr. E.G. Neilson, Northwestern University, Evanston, IL) were grown in DMEM containing $10 \%$ heat inactivated FBS $[25,26]$. Murine bone marrowderived macrophages (BMDM) were obtained following 7 days in culture with DMEM containing 10\% FBS and $10 \%$ L929-cell conditioned medium as a source of macrophage colony-stimulating factor [27, 30]. Serum-starved cells were treated with SOCS1 peptidomimetic $(100 \mu \mathrm{g} / \mathrm{mL}$ miS1), Nox inhibitors $(3 \mathrm{mmol} / \mathrm{L}$ apocynin and $5 \mu \mathrm{mol} / \mathrm{L}$ VAS2870; Sigma-Aldrich) or PI3K inhibitors $(1 \mu \mathrm{mol} / \mathrm{L}$ wortmannin and $10 \mu \mathrm{mol} / \mathrm{L}$ LY294002; Calbiochem) for 90 min prior to stimulation with cytokines $\left(10^{3} \mathrm{U} / \mathrm{mL}\right.$ interferon- $\gamma$ (IFN $\gamma$ ) plus $10^{2} \mathrm{U} / \mathrm{mL}$ interleukin-6 (IL6); PeproTech, Rocky Hill, NJ) or high-glucose concentration (HG, $30 \mathrm{mmol} / \mathrm{L}$ D-glucose). For SOCS1 overexpression experiments, cells were incubated with recombinant adenovirus (Ad-null or Ad-S1; multiplicity of infection =40) for $24 \mathrm{~h}$ before cytokine stimulation [26]. For silencing experiments, cells grown to $60-70 \%$ confluence were transfected with $10-20 \mathrm{nmol} / \mathrm{L}$ of small interfering RNA (siRNA) targeting STAT1, PI3K or negative control scramble siRNA (Ambion, Austin, TX) using 
Table 1 Non-fasting glucose levels in non-diabetic and diabetic mice

\begin{tabular}{|c|c|c|c|c|c|c|c|c|c|}
\hline \multirow[t]{2}{*}{ Days post-STZ } & \multirow{2}{*}{$\begin{array}{l}\text { Non-diabetes } \\
(n=6)\end{array}$} & \multicolumn{5}{|c|}{ Diabetes (early intervention) } & \multicolumn{3}{|c|}{ Diabetes (late intervention) } \\
\hline & & $\begin{array}{l}\text { Control } \\
(n=6)\end{array}$ & $\begin{array}{l}\text { Ad-null } \\
(n=8)\end{array}$ & $\begin{array}{l}\text { Ad-S1 } \\
(n=8)\end{array}$ & $\begin{array}{l}\text { Vehicle } \\
(n=6)\end{array}$ & $\begin{array}{l}\operatorname{miS} 1 \\
(n=6)\end{array}$ & $\begin{array}{l}\text { Vehicle } \\
(n=10)\end{array}$ & $\begin{array}{l}\text { Mut } \\
(n=7)\end{array}$ & $\begin{array}{l}\operatorname{miS} 1 \\
(n=10)\end{array}$ \\
\hline 0 & $7.1 \pm 0.4$ & $7.2 \pm 0.4$ & $5.1 \pm 0.6$ & $7.3 \pm 0.6$ & $6.5 \pm 0.6$ & $6.3 \pm 0.7$ & $6.9 \pm 0.9$ & $6.2 \pm 0.4$ & $6.4 \pm 0.6$ \\
\hline 10 & $6.8 \pm 0.9$ & $25.4 \pm 2.7 *$ & $22.8 \pm 2.0^{*}$ & $23.0 \pm 1.4 *$ & $22.4 \pm 1.9 *$ & $22.8 \pm 2.0^{*}$ & $23.2 \pm 3.7 *$ & $21.6 \pm 2.0^{*}$ & $22.1 \pm 3.9 *$ \\
\hline 21 & $7.1 \pm 1.0$ & $27.6 \pm 0.8^{*}$ & $26.5 \pm 1.4^{*}$ & $29.8 \pm 2.1 *$ & $23.1 \pm 2.7 *$ & $26.4 \pm 3.1^{*}$ & $23.1 \pm 2.8^{*}$ & $22.9 \pm 2.8^{*}$ & $26.1 \pm 0.7 *$ \\
\hline 41 & $8.5 \pm 1.1$ & $28.3 \pm 1.0^{*}$ & $29.6 \pm 0.8^{*}$ & $31.5 \pm 1.1 *$ & $26.8 \pm 2.3^{*}$ & $26.0 \pm 1.2^{*}$ & $27.2 \pm 2.7^{*}$ & $29.9 \pm 2.2^{*}$ & $28.7 \pm 2.1 *$ \\
\hline 63 & $8.0 \pm 0.7$ & -- & - & - & - & - & $28.3 \pm 1.7^{*}$ & $26.4 \pm 2.7 *$ & $26.4 \pm 4.1 *$ \\
\hline 83 & $6.5 \pm 0.2$ & - & - & - & - & - & $30.1 \pm 2.2 *$ & $31.3 \pm 1.7^{*}$ & $28.8 \pm 1.8^{*}$ \\
\hline
\end{tabular}

Blood glucose values are expressed as $\mathrm{mmol} / \mathrm{L}$

$* P<0.05$ vs day 0

Lipofectamine RNAiMAX reagent (Life Technologies). The knockdown of STAT1 and PI3K expression was confirmed by western blot.

\section{Measurement of ROS generation in vitro}

Cells seeded on glass coverslips were loaded with $2 \mu \mathrm{mol} / \mathrm{L}$ DHE in Krebs-Ringer-HEPES buffer (10 mmol/L HEPES $\mathrm{pH} 7.4,119 \mathrm{mmol} / \mathrm{L} \mathrm{NaCl}, 4.7 \mathrm{mmol} / \mathrm{L} \mathrm{KCl}, 1.2 \mathrm{mmol} / \mathrm{L}$ $\mathrm{MgCl}_{2}, 2.5 \mathrm{mmol} / \mathrm{L} \mathrm{CaCl}_{2}, 1.2 \mathrm{mmol} / \mathrm{L} \mathrm{KH}_{2} \mathrm{PO}_{4}, 25 \mathrm{mmol} /$ $\mathrm{L} \mathrm{NaHCO}_{3}$ and $2 \mathrm{mmol} / \mathrm{L}$ glucose) for $30 \mathrm{~min}$ at $37^{\circ} \mathrm{C}$ in the dark, then rinsed and exposed to different stimulation conditions. After DAPI nuclear staining, samples were mounted and analyzed with confocal microscope (Leica, $\lambda$ exc $=488 \mathrm{~nm}, \lambda \mathrm{em}=570-600 \mathrm{~nm}$ ). Nox-dependent ROS generation was measured by lucigenin chemiluminescence assay as described [30]. Briefly, cell homogenates in 50 $\mathrm{mmol} / \mathrm{L}$ phosphate buffer containing $0.01 \mathrm{mmol} / \mathrm{L}$ EDTA, $0.32 \mathrm{~mol} / \mathrm{L}$ sucrose and $0.1 \%$ protease inhibitor cocktail were transferred to Röhren tubes and then $5 \mu \mathrm{mol} / \mathrm{L}$ lucigenin and $100 \mu \mathrm{mol} / \mathrm{L}$ NADPH (Sigma-Aldrich) were added. Chemiluminiscence was measured with a luminometer (Berthold Technologies, Bad Wildbad, Germany) by counting the photon emission at 10-s intervals over 5-10 min and values were normalized per $\mathrm{mg}$ of cell protein.

\section{mRNA expression analysis}

Total RNA from mouse tissues (kidney and aorta) and cultured cells was extracted with TRIzol (Life Technologies). Target gene expressions (Socs1, Kim1, Ccl2, Nox1, Nox2, Nox4, p22 phox $p 47^{\text {phox }}, p 67^{\text {phox }}$, NoxA1, NoxO1, Sod1, Cat, Hmoxl) were analyzed by real-time PCR (Applied Biosystems, Foster City, CA). The mRNA levels were normalized to endogenous control $18 \mathrm{~S}$ rRNA, and then expressed as relative increases vs non-diabetic mice (in vivo studies) or basal conditions (in vitro studies).

\section{Western blot assay}

Total proteins were homogenized in buffer containing $1 \%$ Triton X-100, 0.5\% NP-40 and protease inhibitors. Cytosol, membrane, and nuclear fractions were separated using a compartment protein extraction kit (Millipore). Proteins (25 $\mu \mathrm{g})$ were electrophoresed and then immunoblotted with antibodies against Nox1, Nox4, NoxA1, NoxO1, PI3K/ p85 $\alpha$, phosphorylated-PI3K (P-PI3K)/p85 $\alpha$ (Tyr $^{467}$ ) (Santa Cruz Biotechnology), JAK2, P-JAK2 (Tyr $\left.{ }^{1007 / 1008}\right)$, P-AKT $\left(\mathrm{Ser}^{473}\right)$ (Cell Signaling), STAT1, P-STAT1 (Tyr ${ }^{701}$ ) (Invitrogen), using epidermal growth factor receptor (EGFR), $\beta$ actin (Santa Cruz Biotechnology) and $\alpha$-tubulin (SigmaAldrich) as loading controls. For immunoprecipitation, total cell lysates $(400 \mu \mathrm{g})$ were incubated with PI3K antibody (5 $\left.\mu \mathrm{g}, 16 \mathrm{~h}, 4^{\circ} \mathrm{C}\right)$ followed by protein A/G-Agarose $(20 \mu \mathrm{L}, 2$ h, $4{ }^{\circ} \mathrm{C}$; Santa Cruz Biotechnology); immunoprecipitates were collected by centrifugation, then electrophoresed and immunoblotted for JAK2 and PI3K. Bands were visualized by enhanced chemiluminescence system and quantified (Quantity One, Bio-Rad, Hercules, CA).

\section{Statistics}

Results are presented as individual data points and mean \pm SEM of duplicate/triplicate determinations. Differences across groups were considered significant at $P<0.05$ (ANOVA with Bonferroni's post-hoc test). Pearson's correlation analysis was performed for normally distributed parameters.

\section{Results}

\section{SOCS1-based therapies attenuate oxidative stress in the kidney and aorta of diabetic mice}

To test the antioxidant effects of two delivery systems for SOCS1 induction in an in vivo setting, we induced insulin- 
A Early intervention
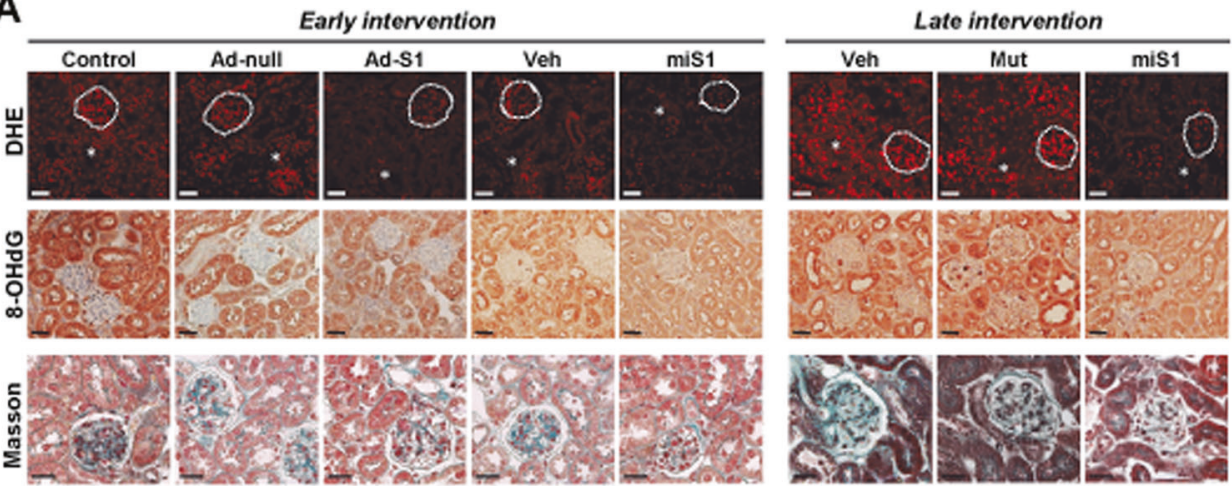

B

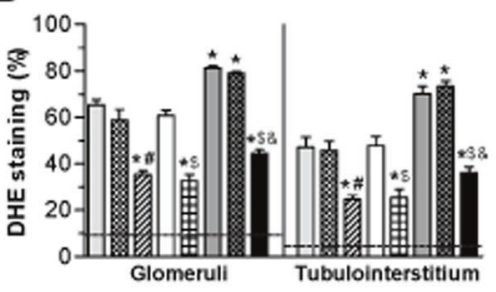

D

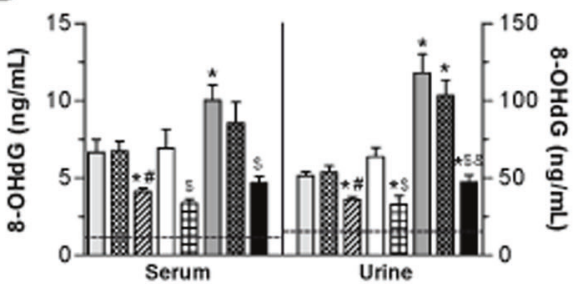

$\mathbf{F}$

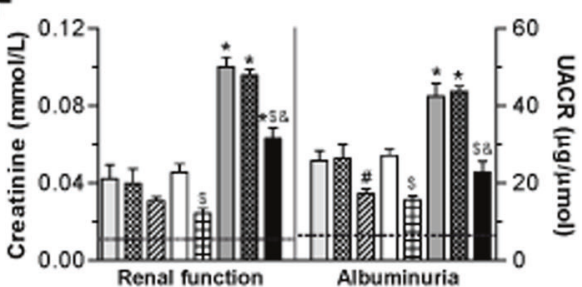

Fig. 1 SOCS1-targeted therapies attenuate oxidative stress damage in diabetic kidneys. a Representative micrographs (scale bar, $20 \mu \mathrm{m}$ ) of $\mathrm{O}_{2} \bullet^{-}$production (DHE fluorescence), oxidative DNA damage (8OHdG immunoperoxidase), and renal morphology (Masson's trichrome staining) in paraffin-embedded kidney sections from diabetic apoE-deficient mice after early intervention with SOCS1-recombinant adenovirus (Control, Ad-null, and Ad-S1 groups) and SOCS1 peptidomimetic (Veh and miS1 groups) and late intervention with peptidomimetic (Veh, Mut, and miS1 groups). White dashed lines and asterisks denote DHE staining in glomeruli and tubules, respectively. b, c Quantification of DHE- (b) and 8-OHdG- (c) positive cells and in renal compartments. d Measurement of $8-\mathrm{OHdG}$ levels in serum and

deficient diabetes mellitus using STZ in apoE-deficient mice. This is a well-established mouse model of concomitant renal and macrovascular disease, whereby diabetic mice develop accelerated renal injury and complex vascular lesions that resemble the morphology seen in patients with

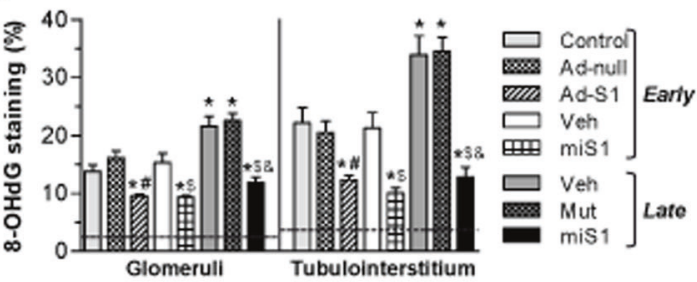

E

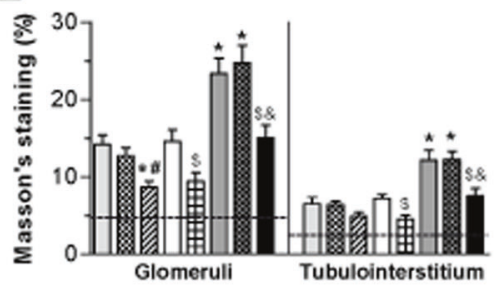

G

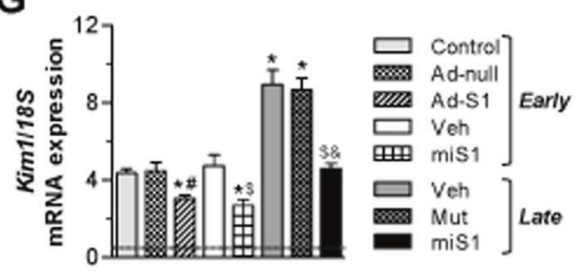

urine samples. e Quantitative assessment of renal fibrosis in Massonstained sections from diabetic mice at early and late diabetes. f Serum creatinine and albuminuria (UACR) levels in the experimental model. g Real-time PCR analysis of tubular injury marker Kim1 in diabetic kidneys; values were calculated after normalization to $18 \mathrm{~S}$ and expressed as relative mRNA level compared with non-diabetic mice. Horizontal dotted lines represent the mean values for non-diabetic mice. Bars represent the mean \pm SEM of 6-8 (early model) and 7-10 (late model) mice per group. Groups were analyzed separately using ANOVA with Bonferroni post-hoc test. ${ }^{*} P<0.05$ vs Control, ${ }^{\sharp} P<$ 0.05 vs Ad-null, ${ }^{\$} P<0.05$ vs respective Veh (early or late model), and ${ }^{\&} P<0.05$ vs Mut

diabetes [29]. At the onset and progression of diabetes, we analyzed markers of oxidative stress, renal dysfunction, and atherosclerosis as major read-outs. In the early intervention model, young diabetic mice ( 8 weeks of age) were treated with SOCS1-encoding adenovirus (Ad-S1) and SOCS1 
peptidomimetic (miS1) and killed 6 weeks later, using saline (Control), empty vector (Ad-null), and vehicle (Veh) as reference groups. In the late intervention model, older mice (22 weeks of age) were treated with SOCS1 peptidomimetic (miS1) for a total of 10 weeks starting at 2 weeks after STZ injection, using vehicle (Veh) and mutant inactive peptide (Mut) as reference groups. Neither early nor late treatments affected hyperglycemia in diabetic mouse groups (Table 1).

Diabetes induction caused progressive oxidative stress in mouse kidney, as demonstrated by increasing $\mathrm{O}_{2} \bullet^{-}$production in glomerular and tubulointerstitial cells (PEGSOD-inhibitable DHE fluorescence) and rising levels of DNA oxidation marker in the kidney, serum, and urine (8-OHdG immunodetection) compared with non-diabetic mice (Fig. 1a-d). Masson's trichrome staining results also confirmed glomerular hypertrophy and increased matrix deposition in glomeruli and tubulointerstitium of diabetic mice (Fig. 1a, e).

During the early phase of diabetes, SOCS1 gene therapy mitigated renal oxidative damage, with lower levels of $\mathrm{O}_{2}{ }^{--}$ and 8-OHdG present in Ad-S1 group compared with Control and Ad-null groups (Fig. 1b-d). Notably, both early and late interventions with SOCS1 peptidomimetic have a potent antioxidant action in diabetic mice, as evidenced by approximately a $50 \%$ decrease of $\mathrm{O}_{2}{ }^{-}$staining in glomeruli and tubulointerstitium of miS1 group compared with Veh or Mut groups (Fig. 1b) and significant reductions of renal and systemic levels of oxidative DNA damage marker 8-OHdG (Fig. 1c, d). Moreover, compared with early-stage gene therapy, SOCS1 peptide treatment at initial and advanced stages showed a more pronounced renoprotective effect in terms of reducing the histological lesions (Masson's quantifications, $\%$ of decrease vs respective controls: Ad-S1, 28 \pm 7 ; early-miS1, $36 \pm 8$; late-miS1, $37 \pm 7$; Fig. 1e) and improving renal function (serum creatinine, $\%$ of decrease: Ad-S1, $27 \pm 5$; early-miS1, $47 \pm 6$; late-miS1, $37 \pm 5$; Fig. 1f), albuminuria (UACR, $\%$ of decrease: Ad-S1, $32 \pm 3$; early-miS1, $42 \pm 4$; late-miS1, 46 \pm 7 ; Fig. 1f), and tubular damage marker (Kim1 mRNA, \% of decrease: Ad-S1, $30 \pm$ 4; early-miS1, $41 \pm 6$; late-miS1, $49 \pm 3$; Fig. $1 \mathrm{~g}$ ) which is consistent with our previous reported effect of peptide therapy in diabetic nephropathy [28]. Further Pearson's analysis in diabetic groups revealed significant correlations between DHE and 8-OHdG staining in both glomeruli and tubulointerstitium, and a positive association with different parameters of kidney damage such as albuminuria, creatinine, fibrosis score, tubular injury, and inflammatory gene expression (Table 2).

Evaluation of diabetic mouse aorta demonstrated that SOCS1-based therapies, and more prominently SOCS1 peptidomimetic, abated oxidative stress in atheroma plaques. Indeed, aortic sections from miS1 groups exhibited lower levels of $\mathrm{O}_{2} \bullet^{-}$and $8-\mathrm{OHdG}$ (Fig. 2a-c) than their
Table 2 Correlation of oxidative stress markers with parameters of renal injury in diabetic mice

\begin{tabular}{|c|c|c|c|c|}
\hline & \multicolumn{2}{|c|}{$\begin{array}{l}\text { ROS PRODUCTION } \\
\text { DHE fluorescence }(\%)\end{array}$} & \multicolumn{2}{|c|}{$\begin{array}{l}\text { DNA OXIDATION } \\
\text { 8-OHdG staining }(\%)\end{array}$} \\
\hline & $\begin{array}{l}\text { GLOM } \\
\text { Pearson's } r \\
(P \text { value })\end{array}$ & $\begin{array}{l}\text { TUB-INT } \\
\text { Pearson's } r \\
(P \text { value })\end{array}$ & $\begin{array}{l}\text { GLOM } \\
\text { Pearson's } r \\
(P \text { value })\end{array}$ & $\begin{array}{l}\text { TUB-INT } \\
\text { Pearson's } r \\
(P \text { value })\end{array}$ \\
\hline $\begin{array}{l}\text { UACR } \\
(\mu \mathrm{g} / \mu \mathrm{mol})\end{array}$ & $\begin{array}{l}0.7293 \\
(<0.0001)\end{array}$ & $\begin{array}{l}0.8162 \\
(<0.0001)\end{array}$ & $\begin{array}{l}0.3498 \\
(0.0290)\end{array}$ & $\begin{array}{l}0.5745 \\
(0.0002)\end{array}$ \\
\hline $\begin{array}{l}\mathrm{srCre} \\
(\mathrm{mmol} / \mathrm{L})\end{array}$ & $\begin{array}{l}0.7753 \\
(<0.0001)\end{array}$ & $\begin{array}{l}0.7716 \\
(<0.0001)\end{array}$ & $\begin{array}{l}0.7759 \\
(<0.0001)\end{array}$ & $\begin{array}{l}0.7521 \\
(<0.0001)\end{array}$ \\
\hline Fibrosis $(\%)$ & $\begin{array}{l}0.7823 \\
(<0.0001)\end{array}$ & $\begin{array}{l}0.7145 \\
(<0.0001)\end{array}$ & $\begin{array}{l}0.8085 \\
(<0.0001)\end{array}$ & $\begin{array}{l}0.6824 \\
(<0.0001)\end{array}$ \\
\hline $\begin{array}{l}\text { Kim1 } \\
\text { mRNA (a.u.) }\end{array}$ & $\begin{array}{l}0.8177 \\
(<0.0001)\end{array}$ & $\begin{array}{l}0.8235 \\
(<0.0001)\end{array}$ & $\begin{array}{l}0.7830 \\
(<0.0001)\end{array}$ & $\begin{array}{l}0.8003 \\
(<0.0001)\end{array}$ \\
\hline $\begin{array}{l}\mathrm{Ccl} 2 \text { mRNA } \\
\text { (a.u.) }\end{array}$ & $\begin{array}{l}0.743 \\
(<0.0001)\end{array}$ & $\begin{array}{l}0.7826 \\
(<0.0001)\end{array}$ & $\begin{array}{l}0.7675 \\
(0.0003)\end{array}$ & $\begin{array}{l}0.7769 \\
(0.0002)\end{array}$ \\
\hline 8-OHdG (\%) & $\begin{array}{l}0.8743 \\
(<0.0001)\end{array}$ & $\begin{array}{l}0.8314 \\
(<0.0001)\end{array}$ & - & - \\
\hline Nox1 (\%) & $\begin{array}{l}0.6680 \\
(<0.0001)\end{array}$ & $\begin{array}{l}0.8125 \\
(<0.0001)\end{array}$ & $\begin{array}{l}0.6052 \\
(<0.0001)\end{array}$ & $\begin{array}{l}0.7897 \\
(<0.0001)\end{array}$ \\
\hline Nox4 (\%) & $\begin{array}{l}0.8115 \\
(<0.0001)\end{array}$ & $\begin{array}{l}0.8064 \\
(<0.0001)\end{array}$ & $\begin{array}{l}0.8135 \\
(<0.0001)\end{array}$ & $\begin{array}{l}0.7787 \\
(<0.0001)\end{array}$ \\
\hline $\begin{array}{l}\text { Sod1 mRNA } \\
\text { (a.u.) }\end{array}$ & $\begin{array}{l}-0.6436 \\
(0.0053)\end{array}$ & $\begin{array}{l}-0.6436 \\
(0.0053)\end{array}$ & $\begin{array}{l}-0.4463 \\
\text { (n.s.) }\end{array}$ & $\begin{array}{l}-0.4392 \\
\text { (n.s.) }\end{array}$ \\
\hline $\begin{array}{l}\text { Hmox1 } \\
\text { mRNA (a.u.) }\end{array}$ & $\begin{array}{l}-0.6491 \\
(0.0048)\end{array}$ & $\begin{array}{l}-0.6491 \\
(0.0048)\end{array}$ & $\begin{array}{c}-0.0221 \\
(0.0221)\end{array}$ & $\begin{array}{l}-0.3956 \\
\text { (n.s.) }\end{array}$ \\
\hline $\begin{array}{l}\operatorname{urTAC} \\
(\mathrm{mmol} / \mathrm{L})\end{array}$ & $\begin{array}{l}-0.7037 \\
(<0.0001)\end{array}$ & $\begin{array}{l}-0.5677 \\
(0.0001)\end{array}$ & $\begin{array}{r}-0.5883 \\
(0.0003)\end{array}$ & $\begin{array}{l}-0.6360 \\
(<0.0001)\end{array}$ \\
\hline
\end{tabular}

Pearson's correlation analysis of DHE and 8-OHdG staining and renal variables in the early and late intervention models $(n=47$ diabetic mice)

GLOM glomeruli, TUB-INT tubulointerstitium, srCre serum creatinine, a.u. arbitrary units, urTAC urine total antioxidant capacity, n.s. non-significant

respective Veh groups, alongside concomitant reductions in atherosclerotic lesion size (Fig. 2a, d), and macrophage content (Moma-2 staining, \% of decrease: Ad-S1, $44 \pm 7$; early-miS1, $63 \pm 8$; late-miS1, $70 \pm 4, P<0.05$ vs respective controls; not shown), which is compatible with our previous findings [27]. Furthermore, Pearson's test revealed statistical correlations of oxidative stress and atherosclerosis parameters such as lesion area (Fig. 2e, f) and inflammatory content (Table 3), thus confirming ROS as a marker of diabetes-driven atherosclerosis.

\section{SOCS1-targeted therapies decrease Nox expression and increase antioxidant activity in diabetic mice}

As NADPH oxidase activity in resident tissue cells and inflammatory cells plays a role in the progression of diabetic vascular complications, we aimed to analyze the effect of SOCS1 treatment on the expression of Nox family members, namely the catalytic subunits (Nox1, Nox2, and Nox4) 
A Early intervention
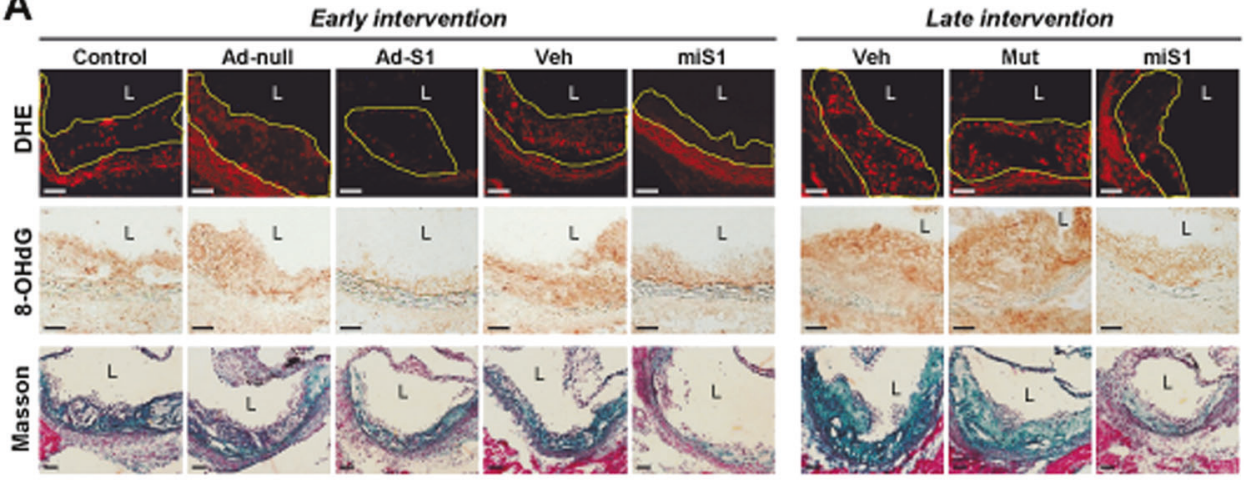

B
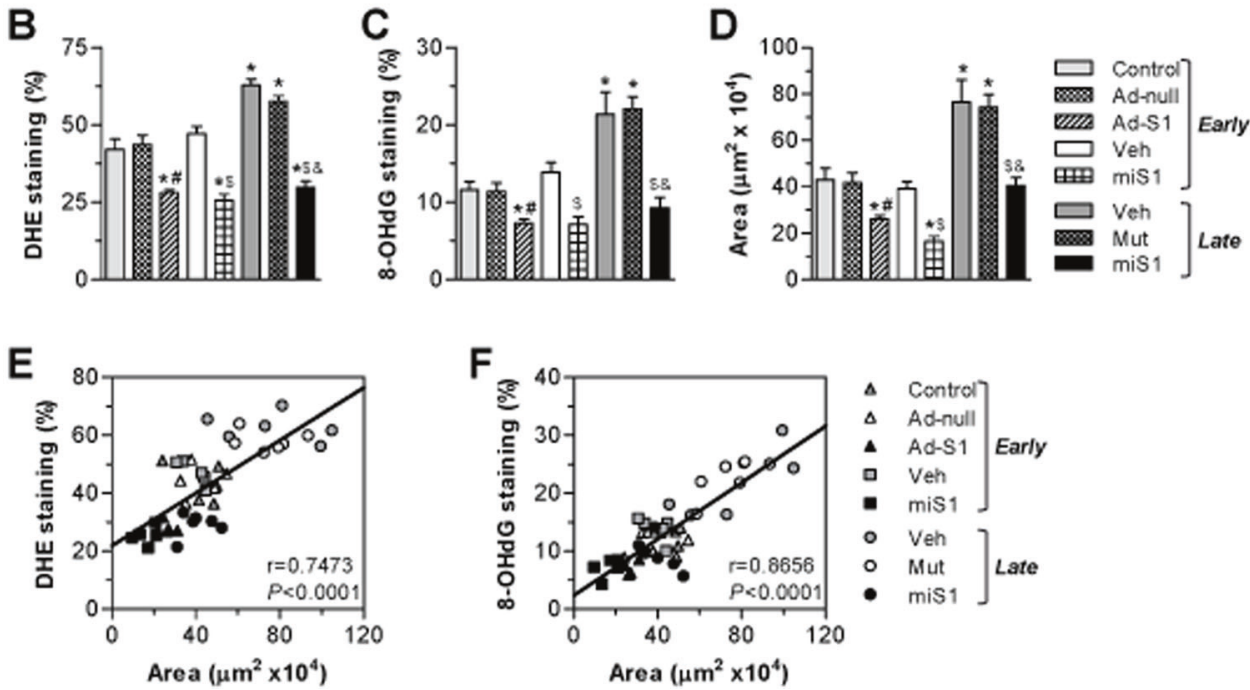

Fig. 2 SOCS1 therapies reduce oxidative stress in diabetic mouse aorta. a Representative images (scale bar, $40 \mu \mathrm{m}$; L Lumen) of $\mathrm{O}_{2}{ }^{\bullet}$ production (DHE fluorescence; yellow dashed lines indicate atheroma), oxidative DNA damage (8-OHdG immunoperoxidase) and atherosclerotic lesion (Masson's trichrome staining) in aortic sections from diabetic apoE-deficient mice after early intervention with SOCS1-recombinant adenovirus (Control, Ad-null, and Ad-S1 groups) and SOCS1 peptidomimetic (Veh and miS1 groups) and late intervention with peptidomimetic (Veh, Mut, and miS1 groups). b, c

and their adaptor subunits (p22 $2^{\text {phox }}, \mathrm{p} 47^{\text {phox }}, \mathrm{p} 67^{\text {phox }}$, NoxO1, and NoxA1). Real-time PCR and immunohistochemical analysis revealed an increased expression of Nox subunits (mainly Nox1 and Nox4) in kidney and aorta of diabetic groups compared with non-diabetic mice (Fig. 3). Moreover, peritoneal macrophages isolated from diabetic mice exhibited higher expression levels of phagocytic Nox2 subunits (Fig. 3a). Remarkably, SOCS1-based gene and peptide therapy caused a significant decrease in the mRNA (Fig. 3a, b) and/or protein (Fig. 3c, d) expression levels of Nox1-4, NoxO1/A1, and $\mathrm{p} 67 / \mathrm{p} 47^{\text {phox }}$ subunits in diabetic mouse samples, but had a minor effect on $\mathrm{p} 22^{\text {phox }}$ expression. As expected, enhanced SOCS1 transgene expression was detected in kidney, aorta, and macrophages of Ad-S1 mice compared with control and Ad-null groups (Fig. 3a).
Summary of quantitative evaluation of DHE- (b) and 8-OHdG- (c) positive cells per lesion area. d Quantitative analysis of atherosclerotic lesion size. Bars are the mean \pm SEM of 6-8 (early model) and 7-10 (late model) mice per group. ${ }^{*} P<0.05$ vs Control, ${ }^{\#} P<0.05$ vs Adnull, ${ }^{\$} P<0.05$ vs respective Veh (early or late model), and ${ }^{\&} P<0.05$ vs Mut. e, f Pearson's correlation analysis of DHE (e) and 8-OHdG (f) staining with atherosclerotic lesion size in mice at early and late intervention

To examine whether SOCS1 effectiveness is linked to improved antioxidant response, we determined the expression levels of SOD1, catalase (Cat), and heme oxygenase-1 (Hmox1), three antioxidant enzymes that reduce redundant ROS and are connected with the cellular anti-inflammatory response [31]. Real-time PCR analysis showed that diabetes increases the transcription of Sodl, Cat, and Hmoxl genes in mouse samples, likely as a compensatory mechanism to reduce oxidative stress (Fig. 4a, b). Notably, SOCS1 gene transfer in early diabetes increased antioxidant gene expression in mouse tissues (Fig. 4a), and this effect was even more evident in the case of SOCS1 peptide administration at both early and late stage of the disease (Fig. 4b). Correspondingly, a parallel analysis of the total antioxidant status revealed that SOCS1 therapies significantly recovered 
Table 3 Correlation of oxidative stress and atherosclerosis parameters in diabetic mice

\begin{tabular}{|c|c|c|c|c|}
\hline & \multicolumn{2}{|c|}{$\begin{array}{l}\text { ROS PRODUCTION } \\
\text { DHE }(\%)\end{array}$} & \multicolumn{2}{|c|}{$\begin{array}{l}\text { DNA OXIDATION } \\
\text { 8-OHdG }(\%)\end{array}$} \\
\hline & Pearson's $r$ & $P$ value & Pearson's $r$ & $P$ value \\
\hline Macrophages (\%) & 0.8194 & $<0.0001$ & 0.7157 & $<0.0001$ \\
\hline Ccl2 mRNA (a.u.) & 0.7458 & 0.0004 & 0.5649 & 0.0146 \\
\hline 8-OHdG (\%) & 0.8295 & $<0.0001$ & - & - \\
\hline Nox1 (\%) & 0.8497 & $<0.0001$ & 0.8153 & $<0.0001$ \\
\hline Nox4 (\%) & 0.7356 & $<0.0001$ & 0.6775 & $<0.0001$ \\
\hline Sod1 mRNA (a.u.) & -0.6187 & 0.0047 & -0.3353 & n.s. \\
\hline Hmox 1 mRNA (a.u.) & -0.6043 & 0.0061 & -0.3756 & n.s. \\
\hline $\operatorname{srTAC}(\mathrm{mmol} / \mathrm{L})$ & -0.7255 & $<0.0001$ & -0.5764 & 0.0002 \\
\hline
\end{tabular}

Pearson's correlation analysis of DHE and 8-OHdG staining and aortic variables in the early and late intervention models $(n=41$ diabetic mice)

srTAC serum total antioxidant capacity, a.u. arbitrary units, n.s. nonsignificant

the impaired capacity of serum and urine to resist oxidation (Fig. 4c). Finally, Pearson's analysis in diabetic groups revealed a strong, negative correlation, between ROS production and antioxidant markers in kidney and aorta of diabetic mice (Tables 2 and 3).

\section{SOCS1 suppresses ROS production and Nox expression in cultured cells}

To corroborate the experimental model, we assessed in vitro the impact of SOCS1-based therapies on the functional responses of vascular cells (primary VSMC), renal tubuloepithelial cells (MCT cell line), and macrophages (primary BMDM) after exposure to inflammatory cytokines $\left(10^{3} \mathrm{U} / \mathrm{mL}\right.$ IFN $\gamma$ plus $10^{2} \mathrm{U} / \mathrm{mL}$ IL6, 1-24 h) or hyperglycemic conditions (HG, $30 \mathrm{mmol} / \mathrm{L}$ glucose, $24 \mathrm{~h}$ ), in an attempt to mimic the diabetic milieu. Confocal microscopy with DHE fluorogenic probe in VSMC and MCT showed that cytokines and $\mathrm{HG}$ produced 3-4-fold intracellular $\mathrm{O}_{2}{ }^{-}$ compared with untreated cells, and that SOCS1 peptide pretreatment significantly decreased this signal increase (Fig. 5a). Lucigenin assay in cell homogenates further confirmed a gradual increase of Nox-dependent $\mathrm{O}_{2} \bullet^{-}$production over time, with significant differences being observed at 1, 3, 6 and $24 \mathrm{~h}$ after cytokine stimulation (Fig. 5b). Notably, cytokine-induced ROS generation by VSMC, MCT, and BMDM was clearly prevented by SOCS1 peptide (Fig. 5b). Moreover, SOCS1 peptide caused a dose-dependent inhibition of Nox activity in HGstimulated MCT (Fig. 5c). Similar results were found in VSMC and macrophages infected with SOCS1overexpressing adenovirus. Indeed, compared with the large amounts of ROS generated after cytokine stimulation in empty vector-transfected cells, Nox activity was significantly reduced by Ad-S1 transfection (Fig. 5d).

Because Nox activation occurs after assembly of the cytosolic regulatory proteins at the plasma membrane, we next analyzed the distribution of Nox subunits between membrane and cytosol. In VSMC, cytokines rapidly promoted membrane translocation of cytosolic NoxA1 and NoxO1 adaptor proteins without altering Nox 1 membrane levels. Moreover, SOCS1 peptide blunted Nox complex assembly, as evidenced by lower NoxA1 and NoxO1 levels in the membrane fraction (Fig. 6a).

The expression levels of Nox genes in a scenario of inflammation and hyperglycemia were further examined by quantitative real-time PCR. In VSMC, cytokine stimulation caused a significant but differential increase in Nox mRNA expression, with NoxA 1 and Nox 4 peaking respectively at 6 and $16 \mathrm{~h}$, Nox 1 and Nox 2 levels remaining elevated until $24 \mathrm{~h}$ (Fig. 6b), whereas p22 $2^{\text {phox }}$ and NoxO1 were unaffected (not shown). In the presence of SOCS1 peptide, however, the Nox components were notably restored, showing a significant decrease compared with cytokines (Fig. 6b). In macrophages, a sustained inhibition of Nox2, p4 $7^{\text {phox }}$, and p6 $67^{\text {phox }}$ mRNA expression over time was observed by pretreatment with SOCS1 peptide (Fig. 6c). Similarly, peptide was also able to prevent the mRNA expression of Nox subunits induced by long-term exposure of MCT to hyperglycemic conditions (Fig. 6d).

\section{Inhibition of PI3K and STAT1 is involved in the antioxidant effect of SOCS1 in vitro}

Because SOCS1 peptidomimetic maintained a substantial inhibition of cytokine-induced ROS generation over a wide range of time (from 1 to $24 \mathrm{~h}$ ), we postulated that this effect might occur via two JAK2-dependent mechanisms: a STAT1-independent PI3K-mediated activation of Nox complex and a STAT1-dependent transcriptional regulation of Nox genes.

We first evaluated the activation of JAK2/STAT1 and JAK2/PI3K/AKT pathways by western blot using phosphospecific antibodies. As shown in Fig. 7a, the Tyr/Ser phosphorylation of JAK2, STAT1, PI3K and AKT induced by cytokines in VSMC was prevented in the presence of SOCS1 peptide. Further coimmunoprecipitation data revealed that SOCS1 inhibited the molecular interaction between JAK2 and PI3K in cytokine-stimulated cells (Fig. 7b). In addition, gene silencing of PI3K and STAT1 employing specific siRNAs clearly demonstrated the involvement of both pathways in Nox-dependent $\mathrm{O}_{2}{ }^{-}$ generation, with a similar inhibitory effect to that of SOCS1 peptide (Fig. 7c).

The contribution of PI3K to ROS production was also tested using specific PI3K inhibitors such as wortmannin 

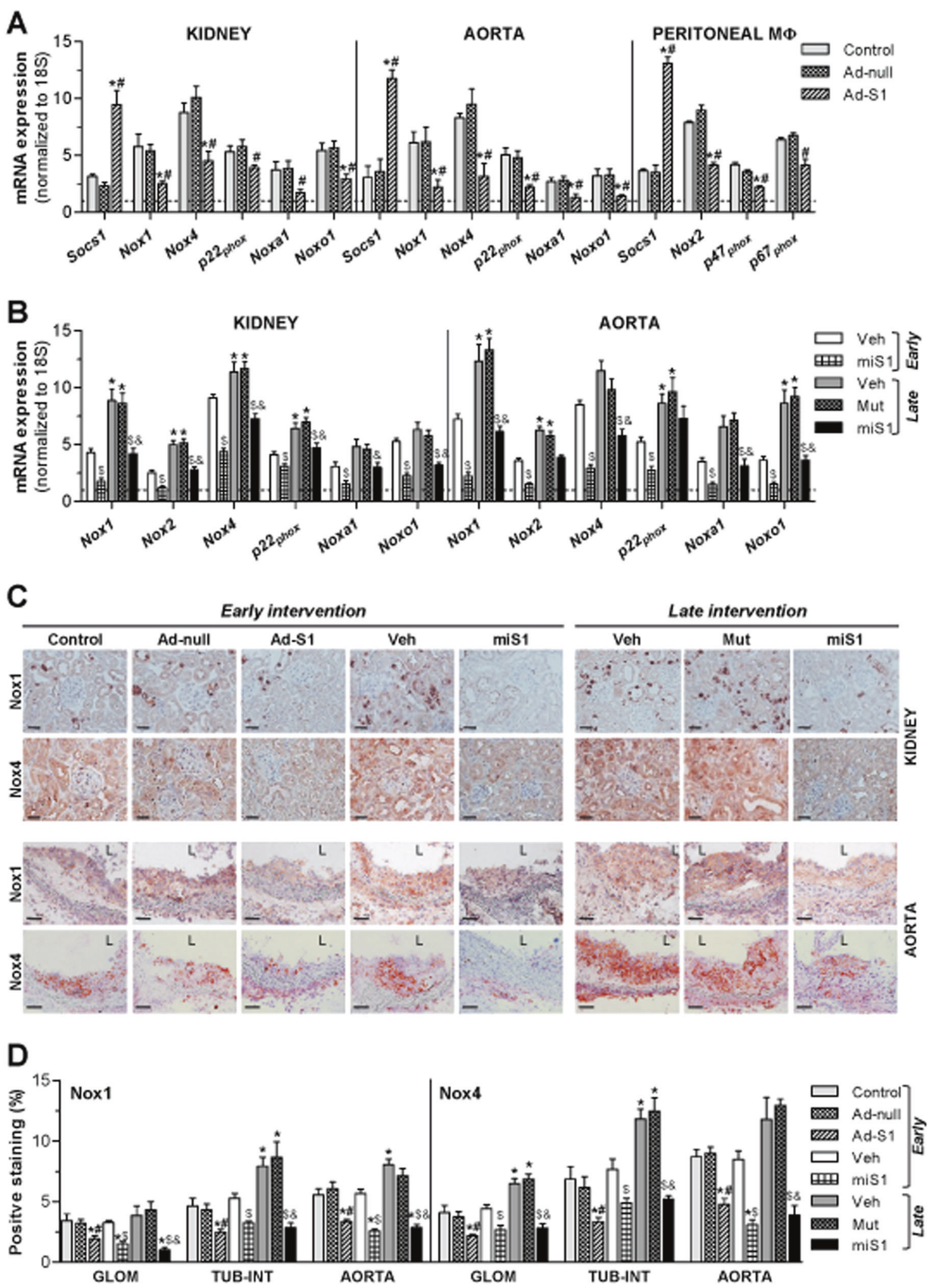

and LY294002. Lucigenin assay in MCT demonstrated that wortmannin blunted Nox-dependent $\mathrm{O}_{2} \bullet^{-}$generation in response to cytokines and $\mathrm{HG}$ to the same extent than
SOCS1 peptide and Nox inhibitors (apocynin and VAS2870) (Fig. 7d). Furthermore, time course studies carried out in cytokine-stimulated VSMC (Fig. 7e) and 
Fig. 3 Effect of SOCS1-based therapies on the expression of Nox subunits in diabetic mice. a, b Gene expression analysis of Nox isoforms in kidney, aorta, and peritoneal macrophages (MФ) from diabetic mice treated with SOCS1-recombinant adenovirus (a) and SOCS1 peptidomimetic (b). Real-time PCR values were normalized to $18 \mathrm{~S}$ rRNA and expressed as relative mRNA level compared with nondiabetic mice (horizontal dotted lines). c Representative micrograph showing immunodetection of Nox 1 and Nox4 isoforms in kidney (scale bar, $20 \mu \mathrm{m}$ ) and aorta (scale bar, $20 \mu \mathrm{m}$; L lumen) of diabetic mice at early and late disease checkpoints. d Quantification of positive cells in kidney (GLOM glomeruli, TUB-INT tubulointerstitium) and aorta. Bars are the mean \pm SEM of $6-10$ mice per group. ${ }^{*} P<0.05$ vs Control, ${ }^{\#} P<0.05$ vs Ad-null, ${ }^{\$} P<0.05$ vs respective Veh (early or late model), and ${ }^{\&} P<0.05$ vs Mut
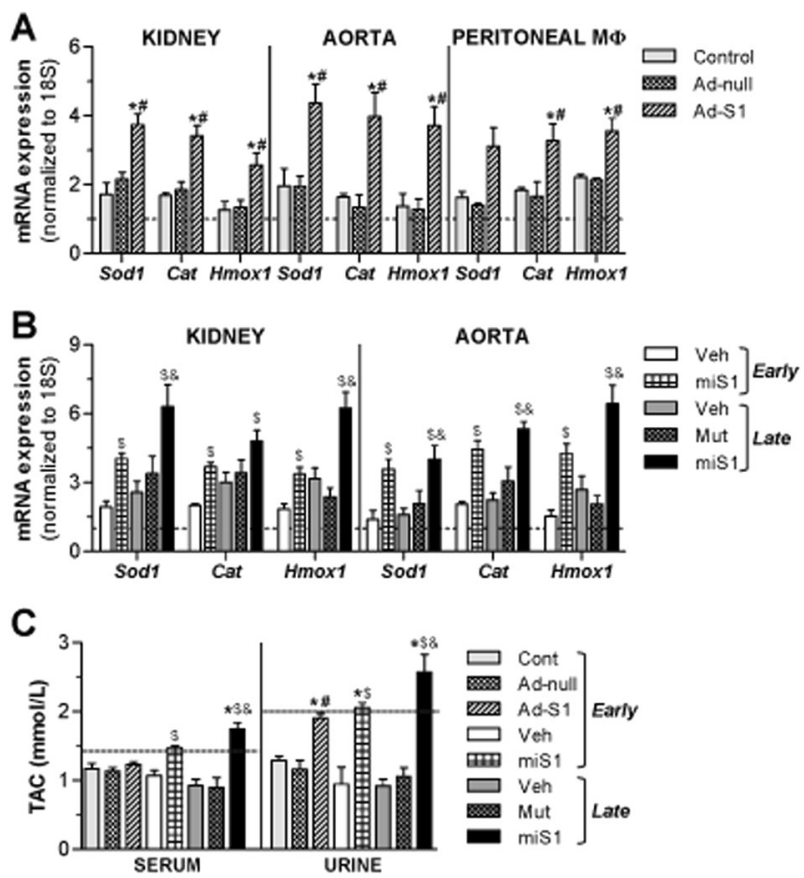

Fig. 4 Antioxidant status of SOCS1-treated mice. a, b Real-time PCR analysis of antioxidant genes in tissue samples and peritoneal macrophages $(\mathrm{M} \Phi)$ from diabetic mice treated with SOCS1-recombinant adenovirus (a) and SOCS1 peptidomimetic (b). Real-time PCR values were calculated after normalization to $18 \mathrm{~S}$ rRNA and expressed as relative mRNA level compared with non-diabetic mice. c Measurement of total antioxidant capacity (TAC) in serum and urine samples. Bars are the mean \pm SEM of 6-10 mice per group. Horizontal dotted lines represent the mean values for non-diabetic mice. ${ }^{*} P<0.05$ vs Control, ${ }^{\#} P<0.05$ vs Ad-null, ${ }^{\$} P<0.05$ vs respective Veh (early or late model), and ${ }^{\&} P<0.05$ vs Mut

macrophages (Fig. 7f) revealed that PI3K inhibitors interfered with short-term $(2 \mathrm{~h})$ but not long-term $(24 \mathrm{~h})$ ROS production, whereas either SOCS1 or apocynin caused significant reductions at both time points. Correspondingly, immunodetection of Nox subunits showed that wortmannin and SOCS1 peptide attenuated short-term regulation of Nox by reducing the amount of membrane-bound NoxA1 (Fig. 7g). However, only SOCS1 was capable to reduce the expression levels of Nox 1 and Nox4 proteins at longer times (Fig. 7g).

\section{Discussion}

The SOCS family of endogenous regulators sits at the crossroad of multiple signaling mechanisms, making them attractive targets for the treatment of inflammatory diseases $[18,19]$. In diabetes-mediated pathologies, alterations of SOCS1 expression associate with cardiovascular risk and progressive renal disease in patients [32, 33]. Animal studies performed by a number of groups, including ours, have shown convincingly that SOCS1 gene absence, leading to sustained STAT activation, aggravates immune and inflammatory responses [23, 25, 34, 35]. Contrarily, SOCS1 induction suppresses pathological JAK/STAT activity and alleviates inflammation, cardiovascular disease and renal dysfunction [24, 26-28, 34, 36]. The present results extend these findings and define a hitherto unknown therapeutic role of SOCS1 in reducing oxidative stress in diabetic micro- and macrovascular complications. We successfully showed that (i) SOCS1-targeted therapies (recombinant adenovirus and peptidomimetic) attenuates $\mathrm{O}_{2}{ }^{-}$production, DNA oxidative damage, and Nox expression in kidney and aorta of diabetic mice, and also boosts local and systemic antioxidant activity; (ii) SOCS1 peptidomimetic rather than gene transfer partially reverses the renal and vascular pathological changes in diabetic mice even in a setting of established disease; (iii) in vitro, SOCS1 peptidomimetic blocks cytokine- and hyperglycemia-induced ROS generation by inhibiting the activation and expression of Nox; (iv) this antioxidant effect is mediated by concomitant inactivation of PI3K- and STAT1-dependent mechanisms.

Many of the key pathogenic processes of type 1 and type 2 diabetes are intimately associated with both oxidative stress and JAK/STAT-dependent signal transduction, ranging from the failure of pancreatic $\beta$ islet cells to the development of the inflammatory response that contributes to the progression of micro- and macrovascular complications $[4,16]$. Nox family is a major source of ROS production and critical mediator of redox signaling in cells from different organs afflicted by the diabetic milieu $[4,6]$. There is increasing evidence that Nox-derived ROS formation plays a key role in the development and progression of micro- and macrovascular complications of diabetes [5]. In mice, total and cell-specific deletion of either Nox 1 or Nox 4 genes attenuates diabetic kidney disease and atherosclerosis [6,11-15], whereas lack of Nox2 does not seem to protect against diabetic nephropathy despite a reduction in infiltrating macrophages [37]. In addition, pharmacological targeting of Nox 1 and Nox 4 using selective and combined inhibitors effectively prevents diabetes-induced damage [5, 11, 14, 38, 39]. In line with this, our results demonstrate upregulated expression of Nox catalytic (Nox1, Nox2, Nox4) and regulatory (NoxA1 and NoxO1) subunits, 
Fig. 5 SOCS1 prevents Noxmediated ROS generation in vitro. a Intracellular detection of $\mathrm{O}_{2}{ }^{-}$in VSMC and MCT pretreated with SOCS1 peptide $(100 \mu \mathrm{g} / \mathrm{mL}, 90 \mathrm{~min})$ before stimulation with either cytokines $\left(10^{3} \mathrm{U} / \mathrm{mL}\right.$ IFN $\gamma$ plus $10^{2} \mathrm{U} / \mathrm{mL}$ IL6, $1 \mathrm{~h})$ or $\mathrm{HG}(30 \mathrm{mmol} / \mathrm{L} \mathrm{D-}$ glucose, $24 \mathrm{~h}$ ). Representative fluorescence images (red, DHE staining; blue, DAPI nuclear staining) and summary of quantification are shown. b Time-response effect of SOCS1 peptide on Nox-dependent ROS generation in VSMC, MCT and BMDM was assessed by lucigenin chemiluminiscence assay. c Dose-dependent curve of SOCS1 peptide on HGstimulated Nox activity in MCT. d Effect of adenovirus-mediated SOCS1 overexpression on Nox activity in cytokine-stimulated VSMC and BMDM. Data expressed as fold increases over basal conditions (arbitrarily set to 1) or lucigenin relative units are the mean \pm SEM of 3-6 independent experiments. $* P<$ 0.05 vs Basal, ${ }^{\#} P<0.05$ vs Cytokines, and ${ }^{\$} P<0.05$ vs $\mathrm{HG}$
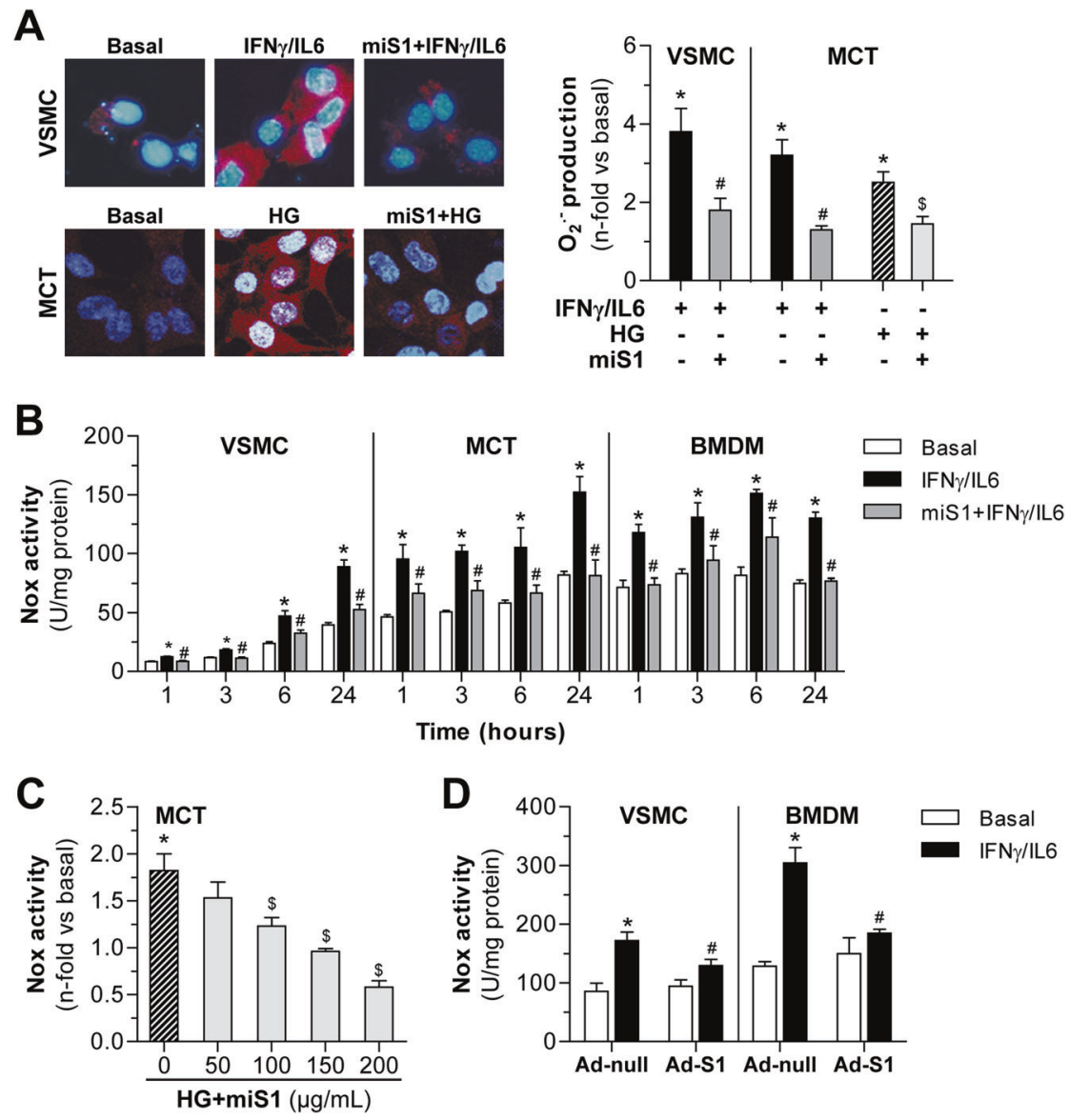

concurrent with intense staining of superoxide-sensitive probe and oxidative DNA damage marker in the aorta, glomeruli, and tubulointerstitium of untreated diabetic mice. These indicators were attenuated by both early and late treatment with SOCS1-based therapies, a condition that was associated with significant reduction of atherosclerosis and kidney damage.

Our study also shows that preventive intervention with the synthetic peptidomimetic corresponding to the kinase inhibitory region of SOCS1 confers superior protection in diabetic mice compared with the adenovirus-mediated overexpression of full-length SOCS1 protein. Consistent with previous reports showing that local and systemic delivery of SOCS genes mitigates early diabetic injury [26, 40], we observed that SOCS1 gene therapy reduced albuminuria in diabetic mice when administered as a preventive intervention (starting immediately after STZ injection), although serum creatinine levels and tubulointerstitial damage were not significantly affected. Noteworthy, SOCS1 peptide was able to improve renal function and attenuate renal and vascular injury in early and established diabetes, which is a more clinically relevant result. The superior activity of SOCS1 peptide therapy over SOCS1 gene therapy in diabetic mice was mirrored by a greater antioxidant effect both systemically and locally, and a significant reduction of inflammatory markers in kidney and aorta. Given the limitations of gene therapy (transfection efficiency, delivery system, short-term expression, and immune complications) that preclude its long-term use in chronic diseases, breakthroughs in other biotechnologies such as peptide drugs are growing in significance during recent years [41]. Several peptide candidates with high specificity, biological activity, and less immunogenic response are already being tested in cancer and inflammatory diseases and also as potential antibiotics and enzyme inhibitors [41]. It is important to highlight that, among the different peptides tested in the last years to modulate JAK/ STAT/SOCS pathway [42], only the cell-permeable SOCS1 peptidomimetic used in this study has been demonstrated to prevent diabetic vascular complications [27, 28].

Concomitant with the reduction of oxidative stress markers, our work also shows that SOCS1-based therapies, independent of treatment period, activates antioxidant defense mechanisms in vivo, as evidenced by increased total antioxidant capacity and higher aortic and renal expression of main antioxidant enzymes, namely SOD1 (the cytosolic CuZn-SOD isoform for superoxide removal), Cat (hydrogen peroxide degrading enzyme), and Hmox1 
Fig. 6 SOCS1 blunts assembly and expression of Nox subunits in cultured cells. a Effect of SOCS1 peptide on cytokineinduced membrane translocation of Nox1A and NoxO1 regulatory subunits in VSMC. Membrane and cytosolic fractions were obtained after $2 \mathrm{~h}$ of stimulation and then immunoblotted for NoxA1, NoxO1, Nox1, $\alpha$-tubulin (cytosolic loading control), and EGFR (membrane loading control). Shown are representative immunoblots and the summary of normalized quantification. b, c Real-time PCR analysis of Nox subunits (normalized to $18 \mathrm{~S}$ ) in cytokinestimulated VSMC (b) and BMDM (c) over time. d Nox mRNA expression levels (normalized to 18S) in MCT at $24 \mathrm{~h}$ of HG incubation. Data expressed as fold increases over basal conditions are the mean \pm SEM of 4-7 independent experiments. $* P<0.05$ vs Basal, ${ }^{\#} P<0.05$ vs Cytokines, and ${ }^{\$} P$ $<0.05$ vs HG
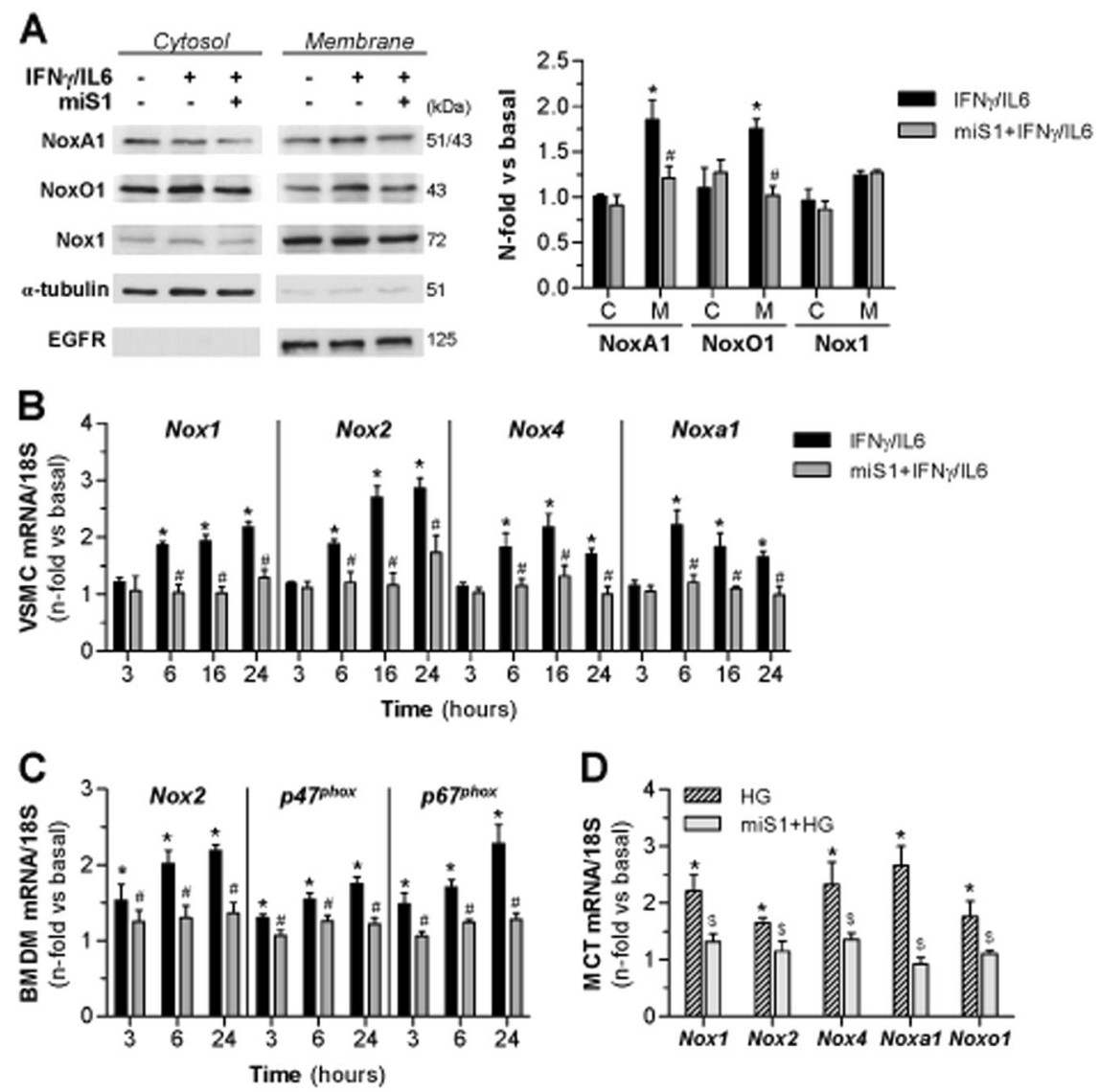

(inducible isoform of heme-degrading enzyme). Clinical studies demonstrate that reduced activity of antioxidant enzymes associates with the progression of chronic kidney disease and cardiovascular events in diabetes [43, 44]. In mice, lack of SOD1, Cat, or Hmox1 worsens the diabetic tissue injury by enhancing oxidative stress, while transgenic expression is renoprotective and retards cardiovascular disease [45-47]. Furthermore, sustained activation of STATs in leukemia cells represses antioxidant gene expression [48], whereas either hepatic deletion of JAK2 or SOCS1 overexpression in lymphocytes protect against oxidative damage by increasing detoxifying enzymes [49, 50]. In agreement, our findings evidence the antioxidant properties of SOCS1-mediated JAK/STAT inhibition through a coordinated cytoprotective response to restore redox balance, although additional studies are needed to delineate the detail mechanism underlying this process.

Evidence indicates that, in addition to direct activation of Nox complex by phosphorylation-dependent pathways, other mechanisms regulating Nox subunit expression (e.g. transcription factors, mRNA stabilization, epigenetic regulation, and post-translational modifications) are involved in excessive ROS generation [7, 8]. In fact, JAK/STAT is proposed as a redox sensitive pathway that participates in the regulation of Nox expression and function in cells under pro-inflammatory conditions, thus constituting a positive feedback loop whereby Nox-derived ROS generation contributes to self-upregulation [8, 16]. Previous in vitro studies demonstrated that intracellular ROS generation regulates JAK/STAT signaling and that Nox inhibition prevents cytokine-mediated phosphorylation of JAK2, STAT1, and STAT3 [16, 51]. Moreover, STAT1/STAT3 transcription factors physically interact with the gene promoter region of Nox 1 and Nox4 for positive upregulation [52]. In vascular cells and macrophages, either JAK2 inhibitor or STAT1/ STAT3 knockdown blunted Nox activity and expression and subsequently hampered ROS production [52-54]. In the context of diabetes, our in vitro results indicate that hyperglycemia and a combination of pro-inflammatory cytokines act on renal, vascular, and phagocytic cells to generate ROS and maintain cell injury, and effect blocked by Nox inhibitors. Furthermore, SOCS1 peptide was able to prevent ROS generation by inhibiting the immediate Nox complex assembly and also the secondary transcriptional activation of Nox gene expression, thus confirming the relationship between JAK/ STAT signaling and Nox-mediated ROS production. Noteworthy, we also observed that PI3K inhibitors blocked shortterm Nox membrane translocation and ROS production but failed to decrease Nox expression, and that SOCS1 peptide blocks JAK2-PI3K interaction and PI3K phosphorylation. 
A

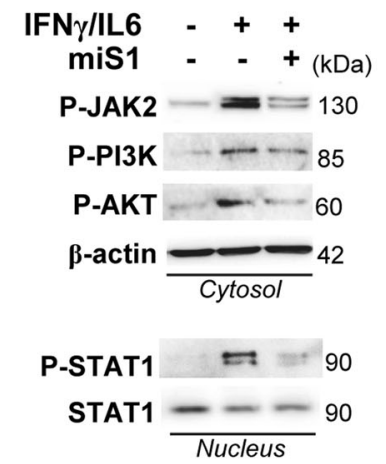

C

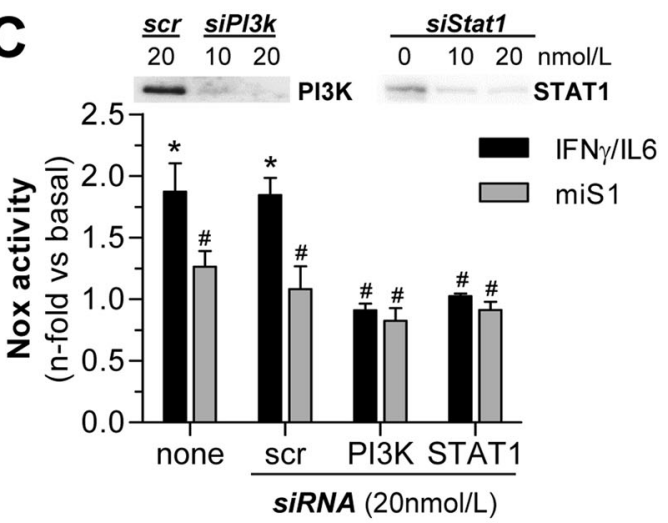

$\mathbf{E}$
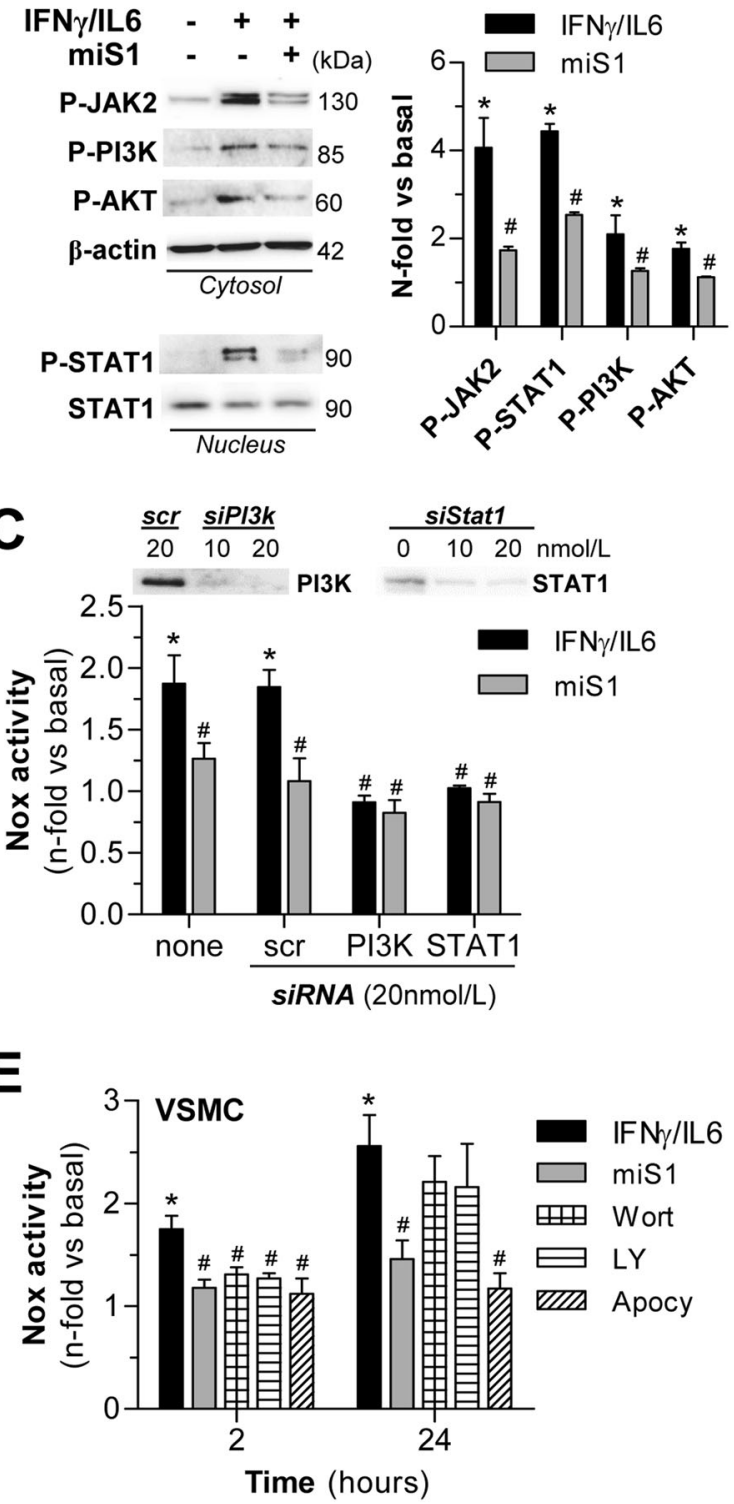

B

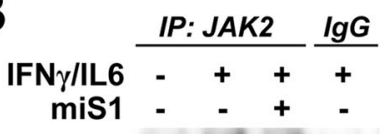

85

WB: PI3K

$130-\cdots$ WB: JAK2

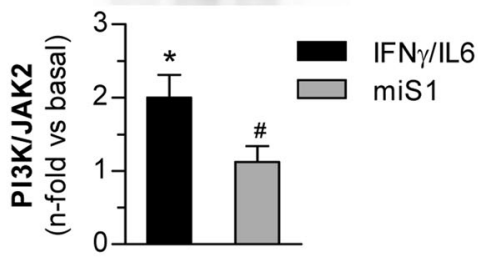

D
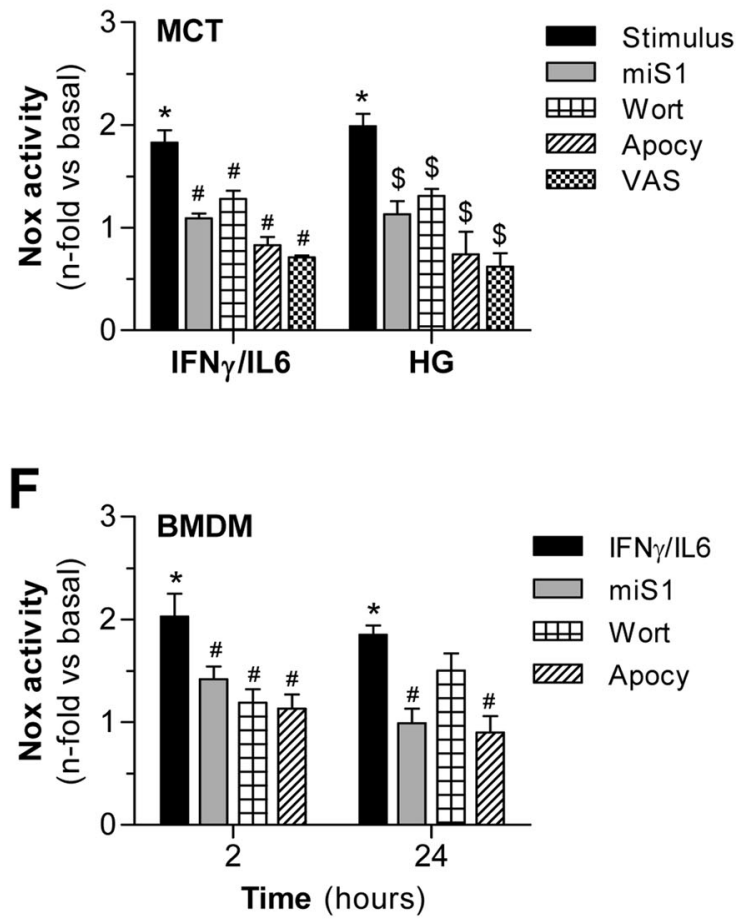

G
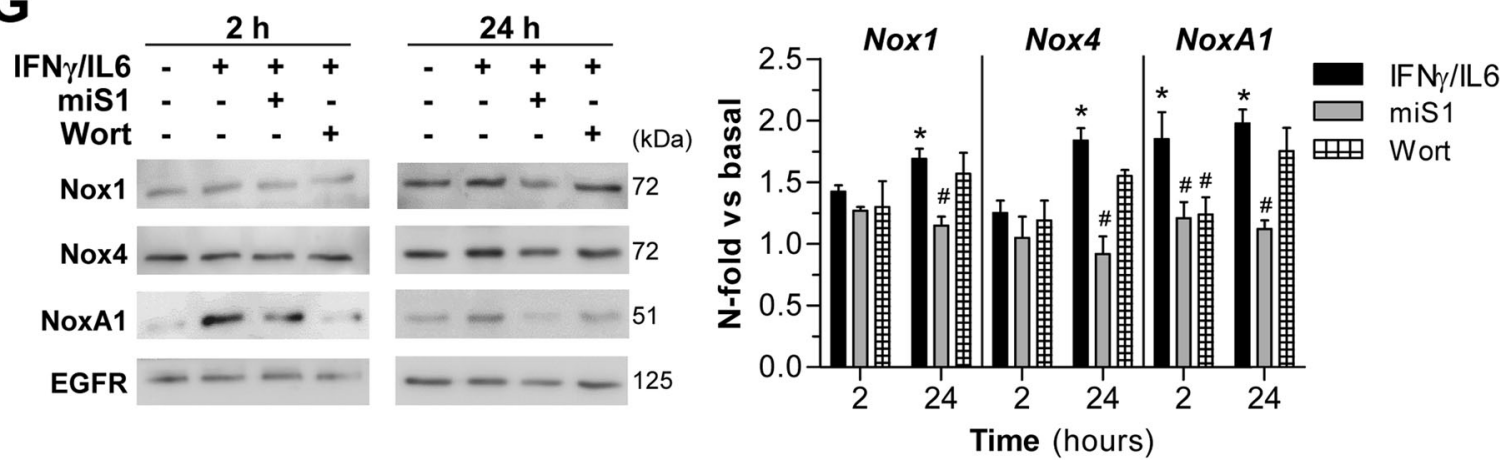

These results indicate a requirement for PI3K in Nox activation, as previously reported in other cell systems [55]. Therefore, we postulate that the inhibition of Nox complex assembly by SOCS1 is the result of PI3K inactivation, whereas downregulated expression of Nox subunits is mediated by STAT1 blockade. 
Fig. 7 Involvement of PI3K and STAT1 in the antioxidant effects of SOCS1 peptide. a Western blot analysis of cytosolic P-JAK2, P-PI3K and P-AKT ( $\beta$-actin, loading control) and nuclear P-STAT1 and STAT1 in VSMC incubated with cytokines $\left(10^{3} \mathrm{U} / \mathrm{mL}\right.$ IFN $\gamma$ plus $10^{2} \mathrm{U} / \mathrm{mL}$ IL6, $2 \mathrm{~h})$ in the presence/absence of SOCS1 peptide $(100 \mu \mathrm{g} / \mathrm{mL})$. b Coimmunoprecipitation (IP) experiments of JAK2 and PI3K in cytokinestimulated VSMC. c VSMC transfected with negative control scramble (scr) or specific siRNAs for PI3K (siPI3k) and STAT1 (siStat1) were stimulated for $2 \mathrm{~h}$ with cytokines with/without SOCS1 peptide. Lucigenin chemiluminescent assay was used to measure Nox-dependent $\mathrm{O}_{2}{ }^{\bullet-}$ production. Inset, PI3K and STAT1 immunoblotting in silenced cells from representative parallel transfection. $\mathbf{d}-\mathbf{f}$ Lucigenin assay in MCT (d), VSMC (e) and macrophages (f) incubated with either cytokines (2 and $24 \mathrm{~h}$ ) or HG $(24 \mathrm{~h}$ ) in the presence of PI3K inhibitors (wortmannin and LY294002), Nox inhibitors (apocynin and VAS2870), and SOCS1 peptide. $\mathbf{g}$ Immunodetection of Nox subunits in membrane fractions from VSMC at two different time points following cytokine stimulation. Representative immunoblots and summary of normalized densitometric quantification are shown. Data expressed as fold increases over basal conditions are the mean \pm SEM of 3-7 experiments. $* P<0.05$ vs Basal, ${ }^{\#} P<0.05$ vs Cytokines, and ${ }^{\$} P<0.05$ vs HG

In conclusion, this study shows that SOCS1-targeted therapies have a protective role against increased oxidative stress under chronic hyperglycemia by altering the expression of enzymes associated with the induction and resolution of oxidative stress in diabetic mice. Approaches based on SOCS1 repletion are worthy of further investigation as an alternative therapeutic antioxidant strategy to limit the progression of diabetic vascular complications.

Acknowledgements This work was supported by Spanish Ministry of Economy and Competitiveness (MINECO/FEDER; SAF2012-38830 and SAF2015-63696-R), Instituto de Salud Carlos III (FIS/FEDER; PI14/00386 and PIE13/00051), Conchita Rabago Foundation (to LLS), Iñigo Alvarez de Toledo Renal Foundation, and Spanish Societies of Nephrology and Arteriosclerosis.

\section{Compliance with ethical standards}

Conflict of interest CGG and JE are inventors on a patent application regarding the peptide. The remaining authors declare that they have no conflict of interest.

\section{References}

1. Nathan DM. Long-term complications of diabetes mellitus. $\mathrm{N}$ Engl J Med. 1993;23:1676-85.

2. Rask-Madsen C, King GL. Vascular complications of diabetes: mechanisms of injury and protective factors. Cell Metab. 2013;1:20-33.

3. Nilsson J, Bengtsson E, Fredrikson GN, et al. Inflammation and immunity in diabetic vascular complications. Curr Opin Lipidol. 2008;5:519-24.

4. Kashihara N, Haruna Y, Kondeti VK, et al. Oxidative stress in diabetic nephropathy. Curr Med Chem. 2010;34:4256-69.

5. Sedeek M, Montezano AC, Hebert RL, et al. Oxidative stress, Nox isoforms and complications of diabetes-potential targets for novel therapies. J Cardiovasc Transl Res. 2012;4:509-18.
6. Gorin Y, Block K. Nox as a target for diabetic complications. Clin Sci (Lond). 2013;8:361-82.

7. Brandes RP, Weissmann N, Schroder K. Nox family NADPH oxidases: molecular mechanisms of activation. Free Radic Biol Med. 2014;76:208-26.

8. Manea SA, Constantin A, Manda G, et al. Regulation of Nox enzymes expression in vascular pathophysiology: focusing on transcription factors and epigenetic mechanisms. Redox Biol. 2015;5:358-66.

9. Lyle AN, Deshpande NN, Taniyama Y, et al. Poldip2, a novel regulator of Nox4 and cytoskeletal integrity in vascular smooth muscle cells. Circ Res. 2009;3:249-59.

10. Manickam N, Patel M, Griendling KK, et al. RhoA/Rho kinase mediates TGF-beta1-induced kidney myofibroblast activation through Poldip2/Nox4-derived reactive oxygen species. Am J Physiol Ren Physiol. 2014;2:F159-F171.

11. Gray SP, Di ME, Okabe J, et al. NADPH oxidase 1 plays a key role in diabetes mellitus-accelerated atherosclerosis. Circulation. 2013;18:1888-902.

12. Gorin Y, Block K, Hernandez J, et al. Nox4 NAD(P)H oxidase mediates hypertrophy and fibronectin expression in the diabetic kidney. J Biol Chem. 2005;47:39616-26.

13. Sedeek M, Callera G, Montezano A, et al. Critical role of Nox4based NADPH oxidase in glucose-induced oxidative stress in the kidney: implications in type 2 diabetic nephropathy. Am J Physiol Ren Physiol. 2010;6:F1348-F1358.

14. Jha JC, Gray SP, Barit D, et al. Genetic targeting or pharmacologic inhibition of NADPH oxidase nox 4 provides renoprotection in long-term diabetic nephropathy. J Am Soc Nephrol. 2014;6:1237-54.

15. Zhu K, Kakehi T, Matsumoto M, et al. NADPH oxidase NOX1 is involved in activation of protein kinase $\mathrm{C}$ and premature senescence in early stage diabetic kidney. Free Radic Biol Med. 2015;83:21-30.

16. Duhe RJ. Redox regulation of Janus kinase: the elephant in the room. JAKSTAT. 2013;4:e26141.

17. Stark GR, Darnell JE Jr.. The JAK-STAT pathway at twenty. Immunity. 2012;4:503-14.

18. Linossi EM, Babon JJ, Hilton DJ, et al. Suppression of cytokine signaling: the SOCS perspective. Cytokine Growth Factor Rev. 2013;3:241-8

19. Trengove MC, Ward AC. SOCS proteins in development and disease. Am J Clin Exp Immunol. 2013;1:1-29.

20. Fernandez-Fernandez B, Ortiz A, Gomez-Guerrero C, et al. Therapeutic approaches to diabetic nephropathy-beyond the RAS. Nat Rev Nephrol. 2014;6:325-46.

21. Brosius FC III, He JC. JAK inhibition and progressive kidney disease. Curr Opin Nephrol Hypertens. 2015;1:88-95.

22. Fineberg D, Jandeleit-Dahm KA, Cooper ME. Diabetic nephropathy: diagnosis and treatment. Nat Rev Endocrinol. 2013;12:713-23.

23. Ortiz-Munoz G, Martin-Ventura JL, Hernandez-Vargas $P$, et al. Suppressors of cytokine signaling modulate JAK/STAT-mediated cell responses during atherosclerosis. Arterioscler Thromb Vasc Biol. 2009;4:525-31.

24. Recio C, Oguiza A, Mallavia B, et al. Gene delivery of suppressors of cytokine signaling (SOCS) inhibits inflammation and atherosclerosis development in mice. Basic Res Cardiol. 2015;2:8.

25. Hernandez-Vargas P, Lopez-Franco O, Sanjuan G, et al. Suppressors of cytokine signaling regulate angiotensin II-activated Janus kinase-signal transducers and activators of transcription pathway in renal cells. J Am Soc Nephrol. 2005;6:1673-83.

26. Ortiz-Munoz G, Lopez-Parra V, Lopez-Franco O, et al. Suppressors of cytokine signaling abrogate diabetic nephropathy. $\mathrm{J}$ Am Soc Nephrol. 2010;5:763-72. 
27. Recio C, Oguiza A, Lazaro I, et al. Suppressor of cytokine signaling 1-derived peptide inhibits Janus kinase/signal transducers and activators of transcription pathway and improves inflammation and atherosclerosis in diabetic mice. Arterioscler Thromb Vasc Biol. 2014;9:1953-60.

28. Recio C, Lazaro I, Oguiza A, et al. Suppressor of cytokine signaling-1 peptidomimetic limits progression of diabetic nephropathy. J Am Soc Nephrol. 2017;2:575-85.

29. Hsueh W, Abel ED, Breslow JL, et al. Recipes for creating animal models of diabetic cardiovascular disease. Circ Res. 2007;10:1415-27.

30. Mallavia B, Oguiza A, Lopez-Franco O, et al. Gene deficiency in activating Fcgamma receptors influences the macrophage phenotypic balance and reduces atherosclerosis in mice. PLoS ONE. 2013;6:e66754.

31. Trachootham D, Lu W, Ogasawara MA, et al. Redox regulation of cell survival. Antioxid Redox Signal. 2008;8:1343-74.

32. Rastmanesh MM, Bluyssen HA, Joles JA, et al. Increased expression of SOCS3 in monocytes and SOCS1 in lymphocytes correlates with progressive loss of renal function and cardiovascular risk factors in chronic kidney disease. Eur J Pharmacol. 2008;1-3:99-104.

33. Yang M, Tian M, Zhang X, et al. Role of the JAK2/STAT3 signaling pathway in the pathogenesis of type 2 diabetes mellitus with macrovascular complications. Oncotarget. 2017;8:96958-69.

34. Grothusen C, Schuett H, Hillmer A, et al. Role of suppressor of cytokine signaling-1 in murine atherosclerosis. PLoS ONE. 2012;12:e51608.

35. Yu CR, Hayashi K, Lee YS, et al. Suppressor of cytokine signaling 1 (SOCS1) mitigates anterior uveitis and confers protection against ocular HSV-1 infection. Inflammation. 2015;2:555-65.

36. Li R, Buras E, Lee J, et al. Gene therapy withneurogenin3, betacellulin and SOCS1 reverses diabetes in NOD mice. Gene Ther. 2015;11:876-82.

37. You YH, Okada S, Ly S, et al. Role of Nox 2 in diabetic kidney disease. Am J Physiol Ren Physiol. 2013;7:F840-F848.

38. Di ME, Gray SP, Chew P, et al. Pharmacological inhibition of NOX reduces atherosclerotic lesions, vascular ROS and immuneinflammatory responses in diabetic Apoe $(-/-)$ mice. Diabetologia. 2014;3:633-42.

39. Gorin Y, Cavaglieri RC, Khazim K, et al. Targeting NADPH oxidase with a novel dual Nox1/Nox4 inhibitor attenuates renal pathology in type 1 diabetes. Am J Physiol Ren Physiol. 2015;11:F1276-F1287.

40. Liu Q, Xing L, Wang L, et al. Therapeutic effects of suppressors of cytokine signaling in diabetic nephropathy. J Histochem Cytochem. 2014;2:119-28.

41. Qvit N, Rubin SJ, Urban TJ, et al. Peptidomimetic therapeutics: scientific approaches and opportunities. Drug Discov Today. 2017;2:454-62.
42. Ahmed CM, Larkin J III, Johnson HM. SOCS1 mimetics and antagonists: a complementary approach to positive and negative regulation of immune function. Front Immunol. 2015;6:183.

43. Hodgkinson AD, Bartlett T, Oates PJ, et al. The response of antioxidant genes to hyperglycemia is abnormal in patients with type 1 diabetes and diabetic nephropathy. Diabetes. 2003;3: 846-51.

44. Colak E, Majkic-Singh N, Stankovic S, et al. Parameters of antioxidative defense in type 2 diabetic patients with cardiovascular complications. Ann Med. 2005;8:613-20.

45. Fujita H, Fujishima H, Takahashi K, et al. SOD1, but not SOD3, deficiency accelerates diabetic renal injury in C57BL/6-Ins2 (Akita) diabetic mice. Metabolism. 2012;12:1714-24.

46. Hwang I, Lee J, Huh JY, et al. Catalase deficiency accelerates diabetic renal injury through peroxisomal dysfunction. Diabetes. 2012;3:728-38.

47. Zhao Y, Zhang L, Qiao Y, et al. Heme oxygenase-1 prevents cardiac dysfunction in streptozotocin-diabetic mice by reducing inflammation, oxidative stress, apoptosis and enhancing autophagy. PLoS ONE. 2013;9:e75927.

48. Bourgeais $J$, Ishac $\mathrm{N}$, Medrzycki $\mathrm{M}$, et al. Oncogenic STAT5 signaling promotes oxidative stress in chronic myeloid leukemia cells by repressing antioxidant defenses. Oncotarget. 2017;26:41876-89.

49. Themanns M, Mueller KM, Kessler SM, et al. Hepatic deletion of Janus kinase 2 counteracts oxidative stress in mice. Sci Rep. 2016;6:34719.

50. Oh J, Hur MW, Lee CE. SOCS1 protects protein tyrosine phosphatases by thioredoxin upregulation and attenuates Jaks to suppress ROS-mediated apoptosis. Oncogene. 2009;35:3145-56.

51. Simon AR, Rai U, Fanburg BL. et al. Activation of the JAKSTAT pathway by reactive oxygen species. Am J Physiol. 1998;6 (Pt 1):C1640-C1652.

52. Manea A, Tanase LI, Raicu M, et al. Jak/STAT signaling pathway regulates nox 1 and nox4-based NADPH oxidase in human aortic smooth muscle cells. Arterioscler Thromb Vasc Biol. 2010;1: 105-12.

53. Fenyo IM, Florea IC, Raicu M, et al. Tyrphostin AG490 reduces NAPDH oxidase activity and expression in the aorta of hypercholesterolemic apolipoprotein E-deficient mice. Vasc Pharmacol. 2011;3-6:100-6.

54. Wang $\mathrm{R}$, Zhang $\mathrm{Y}, \mathrm{Xu} \mathrm{L}$, et al. Protein inhibitor of activated STAT3 suppresses oxidized LDL-induced cell responses during atherosclerosis in apolipoprotein E-deficient mice. Sci Rep. 2016;6:36790.

55. Seshiah PN, Weber DS, Rocic P, et al. Angiotensin II stimulation of NAD(P)H oxidase activity: upstream mediators. Circ Res. 2002;5:406-13. 